\title{
A Rapid Urban Flood Inundation and Damage Assessment Model
}

\author{
Behzad Jamali $^{\mathrm{a}^{*}}$, Roland Löwe ${ }^{\mathrm{c}}$, Peter M. Bach ${ }^{\mathrm{a}, \mathrm{d}, \mathrm{e}}$, Christian Urich ${ }^{\mathrm{a}}$, Karsten Arnbjerg-
}

Nielsen $^{\mathrm{c}}$, Ana Deletic ${ }^{\mathrm{a}, \mathrm{b}}$

*Corresponding Author (email: behzad.jamali@ monash.edu)

${ }^{a}$ Monash Infrastructure Research Institute, Department of Civil Engineering, Monash University, Clayton

3800 VIC, Australia, behzad.jamali@monash.edu, peterbach@gmail.com, christian.urich@monash.edu

${ }^{\mathrm{b}}$ School of Civil and Environmental Engineering, University of New South Wales Sydney, NSW 2052

Australia, a.deletic@unsw.edu.au

${ }^{\mathrm{c}}$ Department of Environmental Engineering, DTU Environment, Technical University of Denmark, Miljøvej,

Building 113, 2800Kgs., Lyngby, Denmark, rolo@env.dtu.dk, karn@env.dtu.dk

${ }^{\mathrm{d}}$ Swiss Federal Institute of Aquatic Science \& Technology (Eawag), Überlandstrasse 133, Dübendorf 8600,

Switzerland

${ }^{\mathrm{e}}$ Institute of Environmental Engineering, ETH Zürich, 8093 Zürich, Switzerland

\section{Abstract}

Urban pluvial flooding is a global challenge that is frequently caused by the lack of available infiltration, retention and drainage capacity in cities. This paper presents RUFIDAM, an urban pluvial flood model, developed using GIS technology with the intention of rapidly estimating flood extent, depth and its associated damage. RUFIDAM integrates a 1D hydraulic drainage network model (SWMM or MOUSE) with an adapted version of rapid flood inundation models. One-metre resolution topographic data was used to identify depressions in an urban catchment. Volume-elevation relationships and minimum elevation between adjacent depressions were determined. Mass balance considerations were then used to simulate movement of water between depressions. Surcharge volumes from the 1D drainage network model were fed statically into the rapid inundation model. The model was tested on three urban catchments located in southeast Melbourne. Results of flood This document is the accepted manuscript version of the following article: 
depth, extent and damage costs were compared to those produced using MIKE FLOOD; a well-known 1D-2D hydrodynamic model. Results showed that RUFIDAM can predict flood extent and accumulated damage cost with acceptable accuracy. Although some variations in the simulated location of flooding were observed, simulation time was reduced by two orders of magnitude compared to MIKE FLOOD. As such, RUFIDAM is suitable for largescale flood studies and risk-based approaches that rely on a large number of simulations.

\section{Keywords}

Flood damage cost; Geographic Information Systems (GIS); hydrodynamic modelling; MIKE FLOOD; MOUSE; SWMM

\section{Introduction}

Global climate is changing with increases in the frequency and intensity of extreme events, such as coastal flooding, extreme precipitation and heat waves already observed (IPCC, 2014). This, together with urbanisation and land use change, will cause even more severe floods and damage to urban areas in the near future. However, it is neither practically nor economically feasible to make urban areas completely free from flooding (CSIRO, 2000; Zhou et al., 2012). For example, it is difficult to protect against minor frequent floods, although we know that the cumulative cost (over time) of these small events might be comparable to, or even larger than, extreme yet infrequent floods (Moftakhari et al., 2017). Adaptation has seen a shift towards implementing a range of novel solutions, (e.g. green infrastructure or real-time control solutions), rather than "fighting" against the forces of nature by building traditional large structures (Mimura et al., 2014). That said, it has been speculated that while potentially beneficial for minor frequent floods, novel measures might not be suitable for the mitigation of extreme cases. Consequently, water utilities and local municipalities are recognising the need to develop "integrated" flood management plans and 
strategies to minimise flood hazard and build flood resilience (e.g. Melbourne Water, 2007) by evaluating both traditional and novel flood protection solutions.

To support this process, the utilisation of computer models to simulate flood extent, depth, duration and flow velocity and their associated damages, as well as effectiveness of different solutions, is paramount. Ideally, planning for flood risk mitigation should be supported by many flooding scenarios (i.e. future climates and urbanisation rates) and alternative solutions (traditional and novel) with respect to uncertain future conditions, as well as their possible consequences and damages (Apel et al., 2006). For example, exploratory modelling (Bankes, 1993), is used for analysing many scenarios with a high level of future uncertainties (e.g. Löwe et al., 2017; Urich et al., 2013). To ensure accuracy in the modelling, we need to continuously simulate these selected scenarios over time - e.g. continuous simulation is crucial for the assessment of green infrastructure flood benefits since they mainly protect against minor but frequent flooding episodes. This approach should consider a whole range of storm types (in terms of magnitude, intensity and duration) over a long time period (e.g. 50 to 100 Years). Additionally, it is able to see the effect of antecedent conditions, such as the retention/detention storage available prior to a storm, an important consideration in capacitive catchments (Kuczera et al., 2006; Rahman et al., 1998; Rahman et al., 2002).

Urban pluvial floods are generally caused by a lack of drainage capacity. This is especially true during high intensity rainfall where free flow to the underground drainage network (typically called the "minor system") becomes pressurised and the water level rises aboveground causing surcharge in manholes or sewer inlets. The surcharged flow subsequently spreads across the surface flow network, called "major systems", which usually includes roads, footpaths, ground depressions and small water courses (Maksimović et al., 2009). The dynamic interaction of minor and major systems, known as the "dual-drainage concept" 
(Djordjević et al., 1999; Djordjević et al., 2005), is represented in urban flood models in various ways and with different levels of complexities. The most detailed representation of this interaction belongs to 1D-2D models, where a one dimensional (1D) drainage network model is coupled with a two dimensional (2D) overland flow model. MIKE FLOOD (DHI, 2013), SOBEK (Deltares, 2017), XPSWMM (XPSolutions, 2017) and TUFLOW (WBM, 2008) are examples of commercially available models. These detailed flood models can simulate flood characteristics with great intricacy, however they are often computationally intensive and, occasionally, numerically unstable (Leandro and Martins, 2016; Lhomme et al., 2006; Teng et al., 2017; Zhang and Pan, 2014).

Due to this practical limitation, flood mitigation studies that use detailed 1D-2D models are often reduced to a limited number of simulations, with performance of each measure evaluated against predefined storm events (i.e. design rainfall) and future conditions. Conversely, simplified models reduce flood simulation time in different ways. However, this speed-up usually comes at the expense of accuracy loss. According to the concept of "fit for purpose model", we should be pragmatic when selecting a model for flood simulation: a fit for purpose model is a model that predicts the required results within the desired level of accuracy and manageable amount of time and computational expense (Guillaume and Jakeman, 2012; Haasnoot et al., 2014; Wright and Esward, 2013).

Attempts to improve the computational performance of flood models can be classified into the following three categories:

1. Model simplification: reducing model structural complexities by incorporating simpler representations of processes. Examples include: Simplifying 2D shallow water equations by omitting certain terms such as inertia (Bates and De Roo, 2000; Bates et al., 2010; Seyoum Solomon et al., 2012); replacing complex 2D surface flow models with 1D models composed of surface depressions and overland flow paths (known as 
1D-1D models) (e.g. Maksimović et al., 2009; Mark et al., 2004); using Cellular Automata (CA) approaches instead of solving shallow water equations in the modelling of 2D overland flows (Dottori and Todini, 2011; Ghimire et al., 2013; Guidolin et al., 2016) as well as their application in 1D drainage networks (Austin et al., 2014) and 1D2D dual drainage systems such as CADDIES model (Guidolin et al., 2012); using highly simplified conceptual models known as rapid inundation models (Bernini and Franchini, 2013; Krupka, 2009; Lhomme et al., 2008) or sometimes considered as 0term models (Néelz and Pender, 2013); and using empirical/data driven surrogate models (Wolfs and Willems, 2013).

2. Detail reduction: using less detailed data or bigger time steps, reducing model input details and/or simulation time-step, e.g. using lower resolution topographic data (Cook and Merwade, 2009; Fewtrell et al., 2008; Savage et al., 2016) or simplified drainage networks (Davidsen et al., 2017).

3. Maximum use of computational resources: parallel computing, code parallelisation, and utilising graphics processing units (GPU) in 1D (Burger et al., 2014) and 2D models (Kalyanapu et al., 2011; Leandro et al., 2014; Vacondio et al., 2014; Zhang et al., 2014b) and using remote distributed computers or Cloud computing (Glenis et al., 2013).

One method can be implemented independently or together with methods in other categories. The reduction in simulation time can vary by orders of magnitude depending on the method used. Among others, rapid flood inundation models and empirical models generally have lower simulation time, in the order of seconds or a few minutes (Bernini and Franchini, 2013; Krupka, 2009; Néelz and Pender, 2010; Néelz and Pender, 2013), which makes them a potential choice when many simulations are required. 
Rapid inundation models divide the 2D surface domain into elementary areas called Impact Zones (IZs) (Lhomme et al., 2008) representing local depressions. Flood water fills these depressions and spills towards neighbouring depressions until all flood water is spread over the ground surface. These models provide more computational speed by disregarding the temporal evolution of the flood hydraulic process (Bernini and Franchini, 2013; Gouldby et al., 2008; Krupka et al., 2007; Lhomme et al., 2008). These models are solely based on solving water balance equations and only predict the final and maximum flood extent and its associated depth. These indicators nevertheless represent the most important characteristics that are used for flood risk assessment (Bernini and Franchini, 2013; Krupka, 2009; Lhomme et al., 2008). Rapid inundation models are particularly suitable for large study areas and/or stochastic modelling for probabilistic flood risk assessment (Néelz and Pender, 2013; Teng et al., 2017). Examples of these models developed for simulating fluvial flooding (where the flood source is from a river or dike-breach) are: RFIM ${ }^{1}$ (Krupka et al., 2007), RFSM ${ }^{2}$ (Gouldby et al., 2008) and its modified versions (Bernini and Franchini, 2013; Lhomme et al., 2008), and FCDC ${ }^{3}$ (Zhang et al., 2014a). Models that are developed for simulating pluvial flooding (where flooding is mainly triggered by the lack of storm drainage network capacity) include: GUFIM ${ }^{4}$ (Chen et al., 2009) and USISM$^{5}$ (Zhang and Pan, 2014). GUFIM and USISM have a storm runoff model to estimate surface runoff, which is the cumulative rainfall volume in excess of infiltration and the drainage network's capacity. This runoff then serves as input to the inundation model.

While all rapid inundation methods utilise the same concept in their routine for generating IZs, there are variations in their flood spreading routines. For example, the RFIM (Krupka,

\footnotetext{
${ }^{1}$ Rapid Flood Inundation Model (RFIM)

${ }^{2}$ Rapid Flood Spreading Model (RFSM)

${ }^{3}$ Flood-Connected Domain Calculation (FCDC)

${ }^{4}$ GIS-based Urban Flood Inundation Model (GUFIM)

${ }^{5}$ Storm Inundation Simulation Method (USISM)
} 
2009) and the earlier version of RFSM (Gouldby et al., 2008) implemented a one-directional spilling flood inundation routine in which an IZ with excess volume only spills towards the neighbouring IZ(s) that have the lowest communication level. By incorporating more physical processes into RFSM, Lhomme et al. (2008) introduced a multi-directional spilling routine. In their new method, spilling towards neighbouring IZ(s) is determined by comparing the communication levels to a calculated water level, which considers the effect of IZ shape on the speed of filling and impact of surface friction on the spilling dynamics. Thus, water can spill towards more than one neighbouring IZs.

Current rapid inundation models are used to simulate fluvial flooding, where the flood source is from a river or dike-breach. The flood inundation routine in these models starts with spreading flood from the specified breach point and estimates its extent. However, the application of the rapid inundation models for urban pluvial flood inundation (where flooding is mainly generated by surcharges from the drainage network manholes) has not yet been investigated. In the case of urban pluvial flooding, surcharges from drainage network manholes can occur at many locations and surface inundation generated by different manholes can meet each other in several locations. ISIS FAST model $(\mathrm{CH} 2 \mathrm{M}$, 2013) is a commercial package that was developed based on the concept of rapid flood inundation models. The 'Dynamic Linked' version of ISIS FAST model is able to simulate urban pluvial flooding by creating a dynamic linking with a 1D drainage network model. The rapid flood inundation model implemented in the dynamic mode however, solves the Manning's equation (and therefore the temporal evolution of flooding) instead of using simple volume balance methods. The Dynamic Linked ISIS FAST model therefore represents a dynamic 1D-2D model that uses a more complex rapid flood inundation model. To our knowledge there are no other rapid inundation models that attempt to couple a 1D drainage network model to 2D rapid inundation model. 
This study aims to develop and validate an urban pluvial flood inundation model that is fast, yet accurate enough for predicting maximum flood extents (and depths) and their associated damage costs. We named it RUFIDAM - Rapid Urban Flood Inundation and Damage Assessment Model. The main novelty of this study is its advancement of rapid inundation models for applications urban pluvial flood assessment. Unlike existing rapid inundation models, RUFIDAM adopts a modified rapid inundation routine and couples it to a $1 \mathrm{D}$ drainage network model in a static way, allowing simulation of inundation caused by surcharging drainage manholes. In other words, we tested the hypothesis that the surcharges predicted by a 1D drainage network model can be fed to a rapid flood inundation model (to reliably characterise the location and magnitude of pluvial flooding in minor-major drainage systems) without considering bi-directional dynamics between the two models. We test the validity of this hypothesis by comparing RUFIDAM against a well-known 1D-2D hydrodynamic urban flood model in series of simulation experiments. Our model was found to predict flood inundation and damage costs with sufficient accuracy, while being considerably faster than existing hydrodynamic models.

\section{Methods}

\subsection{Model formulation}

The RUFIDAM model structure (see Figure 1) has four main modules: (M1) IZs generation; (M2) 1D drainage network model; (M3) rapid flood inundation model; and (M4) damage assessment block. These four blocks are conveniently integrated with a graphical user interface (GUI) developed using the Python Toolbox in ArcGIS. 
The IZs generation module (M1) is responsible for creating the input data for the rapid inundation model. The 1D drainage network model (M2) simulates the rainfall-runoff process and estimates the amount of water that enters the pipe network, then uses a hydraulic simulation engine to calculate surcharges from the subsurface drainage network. These surcharge volumes are imported as input to the rapid flood inundation model (M3). The current version of RUFIDAM is able to use either SWMM (Rossman, 2015) or MOUSE (DHI, 2003); two well-known and well-tested packages. The linkage between 1D drainage network model and rapid flood inundation model is 'static' (c.f. Section M2). The damage assessment module (M4) uses the depth-damage curve method to calculate residential, commercial-industrial and road damage costs based on the inundation depths produced by the rapid inundation model. The next section explains each module in detail.

\section{M1. Impact zones generation}

Rapid inundation models divide the 2D surface domain into elementary areas called Impact Zones (IZs) (Lhomme et al., 2008), representing local depressions. All impact cells within a particular IZ flow towards the accumulation point of that IZ (see Figure 2). The communication point of an IZ determines the communication level at which water spills into the neighbouring IZ (Lhomme et al., 2008). Flood water fills these cells and starts to overflow to adjacent IZs according to the elevation of communication points between two or more neighbouring IZs (Figure 2). An example of the generated IZs from a $1 \mathrm{~m}$ resolution DEM before and after elimination process is illustrated in the supplementary document $\mathrm{S} 1$.

FIGURE 2 APPROXIMATELY HERE 
IZ generation involves generating a network of IZs and their characteristics (list of neighbours, communication points and levels, volume-elevation relationship) based on a digital elevation map using the following steps:

1. Compute flow direction for each cell of the DEM.

2. Identify sinks.

3. Identify watersheds for all sinks (confined areas where all points pour into the same sink).

4. Extract sink boundaries as lines and determine the minimal elevation between neighbouring IZs based on the digital elevation map.

5. Determine the volume stored for different water levels in each IZ based on the digital elevation map

Details of the procedure above is provided in the supplementary document S1. The results of the IZs generation step are output in the form of three tables, which characterise:

- Links between the different IZs, as well as the surface elevations above which water will be exchanged between IZs;

- Surface elevation-volume relationship for each IZ; and

- Links between IZs and nodes of the 1D network model.

\section{M2. 1D drainage network model}

The hydraulic simulation of the underground drainage network in this study was carried out using MOUSE (DHI, 2003) although SWMM was also available. This model also includes a simulation of the rainfall runoff process and thus, an estimation of the amount of surface runoff water that is generated and must be managed by the pipe network and/or above ground. 
RUFIDAM couples 1D drainage network models to the rapid flood inundation model in a static way, where the 1D drainage network model simulation is carried out without a dynamic interaction with the rapid inundation model. At the end of the 1D simulation, the predicted surcharge volumes from each manhole are fed to the rapid inundation model. When the static coupling method is used, the predicted surcharge volumes might differ from those predicted by the dynamically coupled 1D-2D models. Our hypothesis is that urban pluvial flooding is a local phenomenon, meaning the surcharges from the drainage network does not travel long distances over the surface ground. The surcharge volume would rather pond above the manholes and return to the underground network from the same node when there is available capacity (this is already modelled in the 1D drainage network model if the ponding option is selected), or flow downstream and re-enter the drainage network within a short distance. Therefore, it might be possible to simulate pluvial flooding without modelling these local surface flows in detail while maintaining sufficient accuracy and gaining substantial speed-ups. Additionally, the rapid inundation model implemented in RUFIDAM does not represent the temporal evolution of flooding and it cannot provide information on when the surface flow might reach to a downstream intake nodes.

1D drainage network models (such as MOUSE and SWMM) commonly provide different options to handle surcharges when used in a static simulation. In the so-called ponding configuration, it is assumed that water ponds over the surcharging node and will return to the network via the same node when the capacity exists to do so (DHI, 2003). Thus, the water level in the manholes can rise above the terrain level. In the spilling configuration, it is assumed that water leaves the pipe network once the terrain level is reached and not reintroduced into the system. It is not immediately clear, which of these approaches is more suitable as an input for the rapid inundation model. Therefore, both approaches were tested in this paper, applying the standard configurations provided in MOUSE (DHI, 2003). 


\section{M3. Rapid flood inundation model}

The rapid inundation model developed in this study, improves the RFIM algorithm (Krupka, 2009) by incorporating a simpler multiple spilling method used in RFSM (Lhomme et al., 2008) and further adapts it to represent the dynamics of overlapping inundations from multiple manholes. Our rapid inundation model takes the flood volumes from surcharging manholes in the 1D model as input and spreads the flood volume among the IZs based on the elevation of communication points.

Figure 3 sequentially illustrates the inundation routine for three surcharging nodes and eight IZs in ten stages (labelled 1 to 10). The rapid inundation model spreads the surcharge volumes by first filling the IZs that are adjacent to surcharging manholes and spilling the excess water into the neighbouring IZs. The filling/spilling process continues until the surcharged volume from all manholes has been spread across the floodplain. A detailed flowchart of the algorithm developed is represented in the supplementary document S2.

The surcharges from different manholes are treated sequentially and the order of processing the different manholes does not affect the final flood map. Considering the surcharge volume from a single node, the containing IZ is filled up to the lowest communication point with a neighbouring downstream IZ, at which point the remaining surcharge volume is distributed into the downstream IZ, which is again filled up to its lowest communication

point. If the water level in a downstream IZ rises to the same level as in a neighbouring upstream IZ, the two zones are merged and subsequently treated as one (Figure 3, subfigure $3)$.

Before an upstream IZ can overflow into a downstream IZ, which does not yet contain any water, the water level in the upstream IZ needs to rise to a level $\Delta z$ above the communication point (Figure 3, subfigure 2, 4, 5 and 10). The extra driving head $\Delta z$ represents friction losses and it is treated as a parameter of the model (Krupka, 2009; 
Lhomme et al., 2008). The value $\Delta \mathrm{z}$ is not considered in the computation of surcharge volumes as it is assumed that this water will eventually spill to a downstream zone. However, $\Delta \mathrm{z}$ is considered when evaluating maximal water depth in the IZs. If the level of the lowest communication point plus $\Delta \mathrm{z}$ is greater than the level of other communication points, water will spill in multiple direction (Figure 3, iteration 10).

FIGURE 3 APPROXIMATELY HERE

\section{M4. Damage assessment}

The rapid flood inundation model produces a raster map, pixels of which represent water depths. The damage assessment module translates these water depths into damage values. There are various damage assessment frameworks of varying complexity developed internationally (Hammond et al., 2015; Merz et al., 2010; Velasco et al., 2016) and in Australia (M.H., 2010; Olesen et al., 2017). RUFIDAM assesses financial damage cost using the stage-depth damage curve method in which cost is a function of flood depth and area. During the flood damage assessment process, flood inundation maps are overlaid with building and road layers and stage-depth damage curves are applied to estimate direct tangible flood damages RUFIDAM uses stage-damage curves from Australian studies that were identified during a recent literature review (Olesen et al., 2017). The implemented approach in this study uses three curves for three types of land-uses: (1) residential buildings, (2) commercial and industrial buildings and, (3) road areas. We implemented this approach because more detailed damage curves were not available for Australia. 


\subsection{Model testing and application}

\subsubsection{Case study description and data set}

We tested RUFIDAM for three catchments $(\mathrm{C} 1, \mathrm{C} 2$, and $\mathrm{C} 3$ in bottom-right of Figure 4) of different sizes and average slopes, as presented in Figure 4. These catchments are located within the Elster Creek basin in South Eastern Melbourne, which has been subject to frequent pluvial and tidal flooding due to severe storms and urbanisation in low-lying areas. The catchment predominantly contains residential buildings and a small proportion of commercial and industrial buildings distributed across the area (Olesen et al., 2017).

FIGURE 4 APPROXIMATELY HERE

A 1D-2D hydrodynamic model for the catchment was available from a previous project (Davidsen et al., 2017). This model was implemented in MIKE FLOOD (DHI, 2013) by replacing the $2 \mathrm{D}$ surface model with LiDAR DEM data of $1 \mathrm{~m}$ horizontal resolution provided by Geoscience Australia (GA, 2017). The same LiDAR DEM data was also used for RUFIDAM modelling, to create IZs. Supplementary document S3 reports specification of identified IZs for the three catchments. The 1D portion of this 1D-2D hydrodynamic model was used as the 1D drainage network model in RUFIDAM to estimate input surcharge volumes. It included a hydrologic runoff and hydraulic flow simulation engine. Runoff simulations were performed using the so-called 'MOUSE model B'. In this approach, initial losses are considered for runoff from impervious areas, while initial and infiltration losses are considered for pervious areas. A modified Horton approach is applied for modelling infiltration capacity. Runoff transformation is modelled using a kinematic wave approach and all runoff is routed to manholes in the 1D network. Similar to the 1D-2D 
MIKE-FLOOD model implemented in this study, RUFIDAM assumes that all the generated runoff enters the drainage network.

Three design storms with duration of 4.5 hours and return period of 5, 10 and 100-years were extracted from Australian guidelines and used in the simulation experiments.

\subsubsection{Simulation experiments}

As discussed in the following section, we performed a number of simulation experiments using the selected storms to develop and validate RUFIDAM.

\section{D drainage network simulation vs. 1D-2D simulation}

We investigated the impact of implementing a static approach by comparing the results from a 1D simulation of the network to a fully dynamic 1D-2D model. As mentioned in the model description section, the 1D drainage network model can have two different configurations, namely 'ponding' and 'spilling'. It was not obvious whether 1D simulations of the pipe network should apply the spilling or ponding configuration when used in conjunction with the rapid inundation model in a static way. To gain insight into these challenges, we compared simulated total flows in links and maximum water levels in nodes for different static 1D model configurations (ponding and spilling) against the results of the dynamic 1D-2D model (MIKE FLOOD) in the three catchments and for all three storm events. Ideally, the comparison would also consider the volume exchanged between 1D drainage network and surface in both $1 \mathrm{D}$ and $1 \mathrm{D}-2 \mathrm{D}$ simulations. However, this result was not readily available from MIKE FLOOD.

\section{Sensitivity analysis of key model parameters}

We conducted sensitivity analysis to investigate how RUFIDAM predictions varied based on the 1D model setup (ponding and spilling) and to find the range of model parameters (constant extra head $\Delta \mathrm{z}$ and minimum IZ area) for which the best performance indicators 
(see Section 2.2.3) were obtained. This analysis was carried out only in Catchment 1 for the 100-year design storm. We used a grid-search approach with a total of 3000 simulations (2 drainage model setups i.e. spilling and ponding; 50 values for minimum IZ areas ranging between 10 to $2000 \mathrm{~m}^{2}$; and 30 values for $\Delta \mathrm{z}$, ranging from 1 to $30 \mathrm{~cm}$ with $1 \mathrm{~cm}$ intervals). Our initial investigation prior to the sensitivity analysis showed that there was no improvement in the performance indicators for $\Delta \mathrm{z}$ within a 30 to $150 \mathrm{~cm}$ range and for minimum IZ area bigger than $2000 \mathrm{~m}^{2}$. Therefore, we limited our sampling to the range within which we expected to find the best result and increased sampling frequency.

\section{Surface inundation prediction}

To evaluate how our simplified 2D simulation affects predictions of surface inundation, we compared the 2D part of RUFIDAM (the rapid inundation model) against the 2D part of MIKE FLOOD by providing them the same surcharge volumes as the boundary condition. This helped remove the uncertainty of surcharge predictions caused by static simulation of the $1 \mathrm{D}$ drainage network model when compared with the 2D surface models. In both model simulations (rapid inundation model and MIKE FLOOD), 43 source points of inflows to the surface model were considered as boundary conditions. These points and their flows were derived by grouping the 380 nodes surcharging during a 1D network simulation of Catchment 1 for a $\mathrm{T}=100$-year event. The inflow volume at each source point corresponded to the aggregated surcharge volume of the nodes in each group. Since the rapid inundation model does not consider the temporal evolution of flooding, it only requires the total surcharge volumes as input, while we considered a typical surcharge hydrograph (represented in the supplementary document S4) for all source points as input to MIKE FLOOD.

\section{Damage cost prediction}


We evaluated the overall performance of RUFIDAM in the three catchments and for all three storm events by comparing them against 1D-2D MIKE FLOOD results. We used the 1D model setup and rapid inundation model parameters that were suggested by the sensitivity analysis. We also compared total damage cost predicted by RUFIDAM to those predicted using MIKE FLOOD results. The damage cost of flooding were calculated using the stage-depth damage curves provided in Olesen et al. (2017).

\subsubsection{Performance indicators}

Ideally, RUFIDAM's performance should be tested using the measured data of an observed flood event. However, we did not have such a data and therefore compared our model with MIKE FLOOD, a well-known 1D-2D hydrodynamic model. Since RUFIDAM only predicts the final and maximum flood extent and maps, we measured the performance of the model by comparing its results to the maximum flood depth map predicted by MIKE FLOOD model. Unlike RUFIDAM, MIKE FLOOD represents the temporal evolution of flooding, meaning a flood depth map can be reported at each time step of the simulation. The maximum flood extent map represents the highest water depth calculated for each pixel regardless of the time of occurrence.

For all the above scenarios, considering the maximum flood depth maps generated by the 1D-2D simulation in MIKE FLOOD as our baseline, we evaluated two different sets of indicators: (1) indicators for comparing model hydraulic behaviour and (2) indicators for comparing damage cost predictions. The hydraulic indicators, namely Root Mean Square Error (RMSE), Fit, and Bias, are calculated by pixel-by-pixel comparison of the flood depth in both models.

- RMSE for evaluating flood depth prediction performance is calculated as follows: 


$$
R M S E=\sqrt{\frac{\sum_{i=1}^{n}\left(Y_{i}^{R U F I D A M}-Y_{i}^{M I K E ~ F L O O D}\right)^{2}}{n}}
$$

In which $Y_{i}^{R U F I D A M}$ and $Y_{i}^{\text {MIKE FLOOD }}$ are the maximum inundation depth of the $i$ th cell of the RUFIDAM and MIKE FLOOD results, and $\mathrm{n}$ is the number of cells that is wet in at least one of the models. The closer the RMSE is to zero, the better the estimate provided by the rapid model. We defined a pixel as wet if water depth was greater than $5 \mathrm{~cm}$.

- Fit indicator (Lhomme et al., 2008) [\%], was used to measure the agreement between two models in predicating flood extent:

$$
\text { Fit }=100 \times \frac{\mathrm{B}}{\mathrm{B}+\mathrm{C}+\mathrm{D}}
$$

where $\mathrm{B}$ represents the number of pixels inundated in both models, $\mathrm{C}$ is the number of pixels inundated in RUFIDAM but dry in MIKE FLOOD, and D is the number of pixels inundated in MIKE FLOOD but dry in RUFIDAM. A fit value closer to $100 \%$ represents a better agreement in flood extent prediction.

- Bias indicator represents the relative percentage error with respect to the final extent of the flooded area. Positive values indicate overestimation of the extent compared to the expected value, whereas negative values indicate underestimation. Values closer to zero represent smaller errors in predictions (Bernini and Franchini, 2013).

$$
\text { Bias }=100 \times\left(\frac{\mathrm{B}+\mathrm{C}}{\mathrm{B}+\mathrm{D}}-1\right)
$$

The damage cost indicators include:

- Percent Error (PE) of the total damage costs [\%] that measures the relative difference between the total flood damage cost for a catchment (Cost) predicted by the models: 


$$
P E=100 \times \frac{\text { Cost }_{M I K E-F L O O D}-\text { Cost }_{\text {RUFIDAM }}}{\operatorname{Cost}_{M I K E-F L O O D}}
$$

- Fit indicator [\%], was used to measure the agreement between two models in predicting the number of flood damaged buildings at a location. This indicator was calculated using Equation 2 where $\mathrm{B}$ is the number of damaged buildings in both models, $\mathrm{C}$ is the number of damaged buildings in RUFIDAM but unaffected in MIKE FLOOD, and D is the number of damaged buildings in MIKE FLOOD but unaffected in RUFIDAM. A fit value closer to $100 \%$ represents a better spatial agreement in damage prediction.

- Bias indicator for number of flooded buildings [\%], which evaluates the total number of flooded buildings in a catchment, irrespective of their location. This indicator uses Equation 3 with parameters defined for the damage cost fit indicator above. Positive values indicate overestimation in the number of damaged buildings by RUFIDAM compared to MIKE FLOOD, whereas negative values indicate an underestimation.

\section{Results}

\subsection{D drainage network simulation vs. 1D-2D simulation}

Figure 5 compares maximum water levels and total link flow volumes obtained in static 1D drainage network simulations (with ponding and spilling configurations), against those obtained from a dynamic (1D-2D MIKE FLOOD) simulation for a $\mathrm{T}=100$-year event in Catchment 3 (the results for Catchments 1 and 2 were similar as shown in the supplementary document S5). In all three catchments, maximum water levels were positively biased for the 1D simulation with ponding configuration, while they vary around the values obtained from the dynamic simulation when applying the spilling configuration. 
Link flow volumes were overestimated by the $1 \mathrm{D}$ model with ponding configuration as compared to the dynamic simulation and underestimated by the 1D model with spilling configuration. These trends were consistent for all the considered catchments and rain events.

FIGURE 5 APPROXIMATELY HERE

Figure 6 shows a map of differences between maximum water levels (maximum water level in static 1D simulation minus maximum water level in dynamic 1D-2D MIKE FLOOD) and link flow volumes (total link flow in static 1D simulation minus total link flow in dynamic 1D-2D MIKE FLOOD) for a $\mathrm{T}=100$-year event for Catchment 3. In upstream areas, the simulated levels and flows in the spilling method were very similar to the dynamic 1D-2D MIKE FLOOD model, while for the ponding method the upstream values were biased. As water moves downstream, the difference in link flows aggregated, and resulted in a greater difference in the main downstream links. Additionally, higher water levels in the ponding simulation induced upstream pipe flows and thus led to reduced surcharge volumes in upstream nodes.

FIGURE 6 APPROXIMATELY HERE

\subsection{Sensitivity analysis of key model parameters}

Figure 7 shows the result of the sensitivity analysis by comparing results obtained from RUFIDAM with different configurations, against a MIKE FLOOD simulation for a $\mathrm{T}=100$ - 
year event in Catchment 1. This figure used the damage cost prediction performance indicators. Sensitivity analysis using the hydraulic performance indicators is provided in the supplementary document S6. These figures suggest that RUFIDAM was most sensitive to the $\Delta \mathrm{z}$ parameter and minimum IZ area, while the choice of either ponding or spilling configuration of the 1D model had minimal impact on model results. The spilling configuration showed slightly better performance, which is in agreement with the already presented results (section 3.1). In both spilling and ponding options, the impact of minimum IZ area increased with $\Delta \mathrm{z}$ (up to around $10 \mathrm{~cm}$ ), while the influence of $\Delta \mathrm{z}$ did not change with an increase in IZ area. A parameter set should be selected by accounting for all performance indicators. The best PE and highest FIT values were observed for $\Delta \mathrm{z}=12$ to $15 \mathrm{~cm}$, and minimum IZ area between 150 to $250 \mathrm{~m}^{2}$ in both spilling and ponding methods. Bias for the same values were around -12 to 5 percent. As such, these parameter values in combination with 1D model simulations using a spilling configuration were applied.

FIGURE 7 APPROXIMATELY HERE

\subsection{Surface inundation prediction}

Figure 8 shows the flood extent predicted by the rapid inundation model and MIKE FLOOD for the scenario in which 43 nodes were surcharging. The flow paths predicted by the rapid inundation model were very similar to those predicted by MIKE FLOOD. This highlights the ability of the rapid inundation model in predicting the flooding pattern, even if it was over- or underestimating local flooding. Figure 8 also shows a pixel-by-pixel comparison of flood depth between both models. The rapid inundation model performed well in predicting 
higher flood water depth (which can cause significantly higher damage costs). The Fit and Bias values were $48.5 \%$ and $-6 \%$, respectively.

FIGURE 8 APPROXIMATELY HERE

\subsection{Damage cost prediction}

Figure 9 compares the flood damage cost for residential buildings, commercial/industrial buildings and roads in all catchments, estimated using flood inundation maps produced by MIKE FLOOD and RUFIDAM. Generally, RUFIDAM overestimated the total damage cost. The predicted damage for residential buildings was similar across both models, while the difference was higher for commercial/industrial damages. The reason for this discrepancy is that the damage cost of these buildings was more sensitive to changes in water level. Commercial buildings also incur a relatively high damage cost and represent a significant proportion of the total damage costs even though the number of flooded buildings was lower. As the number of commercial/industrial buildings decreases in a catchment, the total damage cost predicted by RUFIDAM approaches the value predicted by MIKE FLOOD. In Catchment 3 no commercial/industrial building was flooded.

\section{FIGURE 9 APPROXIMATELY HERE}

Figure 9 also shows the Fit, Bias and PE indices for each catchment. The Fit index ranges around 40 to 50 percent while the Bias index was in the order of $10 \%$ or less in all cases. Hence, compared to a fully dynamic 1D-2D simulation, we concluded that RUFIDAM was able to reproduce the overall flood extent, while we observed quite widespread variation and 
errors in the locations where flooding was simulated. This is also evident from Figure 10, which compares flood depth and damage maps for the two different simulation methods.

FIGURE 10 APPROXIMATELY HERE

\section{Discussion}

\subsection{D network model configuration as an input to rapid inundation model}

Maximum water level and link flows were higher when the ponding configuration was applied in the 1D simulation as opposed to the spilling configuration. The reason for this behaviour is that higher water levels and thus higher pressure gradients were simulated in the $1 \mathrm{D}$ configuration and that surcharged water will eventually enter the network from the same node when the capacity becomes available. In the spilling configuration, all the surcharged volume is assumed to be lost from the network and water levels cannot rise above the ground level.

In the 1D-2D MIKE FLOOD simulation, part of the surcharged volume will enter from the same node, some will flow downstream and re-enter the network via other nodes and the rest will exit the catchment as surface runoff. Surface water levels can affect the pressure gradients in the pipe network, but the surface water levels above the manholes were usually low. Compared to 1D-2D simulation, the spilling method showed only small variations in water levels and flows through upstream pipes, suggesting that surcharges should occur in a similar location as in the 1D-2D simulation. During sensitivity analysis, slightly better results were obtained for the spilling configuration than for the ponding configuration, while the configuration of 2D parameters had greater impact on model results. This suggests that 
the biggest potential for improving RUFIDAM should be found in the $2 \mathrm{D}$ surface model while a static 1D model can describe the hydraulics of the pipe network with sufficient accuracy.

\subsection{Predicting flood inundation}

Overall, the maximum flood inundation extent predicted by the rapid inundation model were comparable with those predicted by the 1D-2D MIKE-FLOOD hydrodynamic model. The model performs better in areas that have natural depressions than flat topography and therefore tends to predict higher inundation depths better than lower depths (as high depth of flood water is usually formed in areas where there are natural depressions in the surface terrain and flood water can accumulate).

One of the limitations of rapid inundation models is that their simple wetting/drying algorithm tends to leave flooded areas in between IZs (which are natural flow paths) as dry areas. In other words, only locations of ponding water will be reported as flooded areas and the flow paths between two flooded neighbouring IZs will be reported as dry in the final inundation map. As the size of IZs increases (the number of IZs decreases), the amount of dry areas increases. This can be improved by finding possible connecting pathways between IZs using the "rolling ball" technique suggested in the literature (CH2M, 2013; Leitão et al., 2009; Maksimović et al., 2009; van Dijk et al., 2014). Water depth in these dry areas were usually smaller than the minimum threshold level in our depth damage curves. Therefore, this shortage did not significantly affect the total damage cost predictions.

\subsection{Predicting flood damage cost}

The total damage cost predicted by RUFIDAM had good agreement with those based on the MIKE-FLOOD inundation maps, for residential buildings and road areas. However, it was not comparable for commercial/industrial buildings because their damage cost is sensitive to 
flood depth. Estimated Fit index values for flood damage prediction were around 40 to 50 percent in different catchments, indicating RUFIDAM did not perform well in identifying the same buildings flooded in MIKE FLOOD, but was able to predict the overall damage cost within the study area.

In areas like Australian suburbs, where land-use usually does not vary a lot across small distances, local variations in the prediction of flooding will have little impact on total flood damage, particularly compared to the uncertainty from other model inputs such as damage curves, the rainfall, etc. It is important to have a "balanced" level of complexity and uncertainty among each modelling block (e.g. rapid inundation model and damage assessment blocks). In particular, when comparing to the uncertainty resulting from depthdamage functions (de Moel and Aerts, 2011), RUFIDAM provides estimates of total flood damage with sufficient accuracy and a minimum of simulation time and model complexity. de Moel and Aerts (2011) states that while estimating the absolute flood damage cost, estimates for proportional changes in flood damages are much more robust. Therefore, we can expect more confidence when we use RUFIDAM to compare the performance of different flood mitigation measures, rather than predicting absolute damage cost reduction.

\subsection{Computational requirements and simulation speed}

In general, the simulation time of RUFIDAM was less than 15 minutes. This comprises the total time spent for the 1D drainage network, rapid flood inundation model, damage assessment processes and creation of output maps, but does not include the IZ generation process (which we measured separately). Around 40 percent of this time was spent for 1D drainage network simulation (MOUSE simulation time for Catchments 1, 2, and 3 were around 5, 6 and 1 minutes, respectively). The IZs generation process for catchments required between 2 to 10 minutes depending on the catchment size. When running many 
simulations, the IZs generation step need only be carried out once if the change in topography (e.g. city development over time) is not considered.

Figure 11 compares the simulation time of RUFIDAM (excluding IZs generation) and MIKE FLOOD for all catchments and return periods in relation to catchment sizes. Unlike the rapid flood inundation model, MIKE FLOOD uses parallel processing (we used a 6-core CPU computer for MIKE FLOOD simulations). The total simulation time in RUFIDAM is a function of the study area (catchment size), number of IZs, and the amount of surcharge volume to be spread in the rapid inundation model. Figure 11 shows that in general, as the size of the catchment increases, the speed gain increases exponentially.

FIGURE 11APPROXIMATELY HERE

It should be noted that this analysis should also be carried out for DEMs with different resolutions. It is expected that MIKE FLOOD would be significantly quicker when coarser resolution DEMs are used.

\section{Conclusion}

This paper presented RUFIDAM, a GIS based rapid urban pluvial flood inundation and damage assessment model that was designed to run with very short computational and setup time to be used in exploratory modelling and continuous flood simulations. RUFIDAM integrates a 1D drainage network model with a simple and fast volume spreading routine based on only water balance and topography (local depressions).

Results showed that the spilling configuration of the 1D drainage network model (MOUSE) yields hydraulic results that are very similar to those obtain in a 1D-2D simulation. The 
surcharge volumes obtained from such a model are thus an appropriate input to a rapid flood inundation model when land use changes in the catchment are small and summary statistics are the key focus. Our hypothesis that using a 1D drainage network simulation are sufficiently accurate to simulate pluvial flooding without modelling these "local" surface flows in detail was proven to be valid.

The maximum flood inundation extents predicted by RUFIDAM were comparable with those predicted by the 1D-2D MIKE FLOOD especially in areas that have natural depressions and, hence, high water depths. However, local variations of flood areas were observed, leading to deviations about which buildings were considered flooded. However, comparable total flood damages are simulated by RUFIDAM and the 1D-2D model.

RUFIDAM is suitable for flood inundation and damage estimation when the study area is large or a large number of simulations are required (such as risk-based approaches for flood risk assessment or exploratory modelling) and where differences between calculations are more important than accurate calculations of each result.

Future research includes the sensitivity analysis of the model performance to the DEM grid resolution. The model has the potential to represent tidal floods and this capability will be introduced in the future to simulate tidal and pluvial flooding.

\section{Acknowledgements}

The Australia-Indonesia Centre (AIC) has financially supported this research. Melbourne Water and City of Port Phillip kindly provided the catchment data. The authors would like to thank the anonymous reviewers for their valuable comments and suggestions to improve the quality of the paper. 


\section{References}

Apel, H., Thieken, A.H., Merz, B., Blöschl, G., 2006. A Probabilistic Modelling System for Assessing Flood Risks. Natural Hazards, 38(1): 79-100.

Austin, R.J., Chen, A.S., Savić, D.A., Djordjević, S., 2014. Quick and accurate Cellular Automata sewer simulator. Journal of Hydroinformatics, 16(6): 1359-1374.

Bankes, S., 1993. Exploratory Modeling for Policy Analysis. Operations Research, 41(3): 435-449.

Bates, P.D., De Roo, A.P.J., 2000. A simple raster-based model for flood inundation simulation. Journal of Hydrology, 236(1): 54-77.

Bates, P.D., Horritt, M.S., Fewtrell, T.J., 2010. A simple inertial formulation of the shallow water equations for efficient two-dimensional flood inundation modelling. Journal of Hydrology, 387(1): 33-45.

Bernini, A., Franchini, M., 2013. A Rapid Model for Delimiting Flooded Areas. Water Resources Management, 27(10): 3825-3846.

Burger, G., Sitzenfrei, R., Kleidorfer, M., Rauch, W., 2014. Parallel flow routing in SWMM 5. Environmental Modelling \& Software, 53: 27-34.

CH2M, 2013. ISIS FAST.

Chen, J., Hill, A.A., Urbano, L.D., 2009. A GIS-based model for urban flood inundation. Journal of Hydrology, 373(1-2): 184-192.

Cook, A., Merwade, V., 2009. Effect of topographic data, geometric configuration and modeling approach on flood inundation mapping. Journal of Hydrology, 377(1): 131-142.

CSIRO, 2000. Floodplain Management in Australia: Best Practice Guidelines. CSIRO Publishing.

Davidsen, S., Löwe, R., Thrysøe, C., Arnbjerg-Nielsen, K., 2017. Simplification of one-dimensional hydraulic networks by automated processes evaluated on 1D/2D deterministic flood models. Journal of Hydroinformatics.

de Moel, H., Aerts, J.C.J.H., 2011. Effect of uncertainty in land use, damage models and inundation depth on flood damage estimates. Natural Hazards, 58(1): 407-425.

Deltares, 2017. SOBEK Suite.

DHI, 2003. MOUSE User Guide and Reference Manual.

DHI, 2013. MIKE FLOOD - 1D-2D Modelling - User Manual.

Djordjević, S., Prodanović, D., Maksimović, Č., 1999. An approach to simulation of dual drainage. Water Science and Technology, 39(9): 95-103.

Djordjević, S., Prodanović, D., Maksimović, Č., Ivetić, M., Savić, D., 2005. SIPSON-Simulation of interaction between pipe flow and surface overland flow in networks. Water Sci. Technol., 52: 275 .

Dottori, F., Todini, E., 2011. Developments of a flood inundation model based on the cellular automata approach: Testing different methods to improve model performance. Physics and Chemistry of the Earth, Parts A/B/C, 36(7): 266-280.

Fewtrell, T.J., Bates, P.D., Horritt, M., Hunter, N.M., 2008. Evaluating the effect of scale in flood inundation modelling in urban environments. Hydrological Processes, 22(26): 5107-5118.

GA, 2017. 
Ghimire, B. et al., 2013. Formulation of a fast 2D urban pluvial flood model using a cellular automata approach. Journal of Hydroinformatics, 15(3): 676-686.

Glenis, V., McGough, A.S., Kutija, V., Kilsby, C., Woodman, S., 2013. Flood modelling for cities using Cloud computing. Journal of Cloud Computing: Advances, Systems and Applications, 2(1): 7.

Gouldby, B., Sayers, P., Mulet-Marti, J., Hassan, M.A.A.M., Benwell, D., 2008. A methodology for regional-scale flood risk assessment. Proceedings of the Institution of Civil Engineers Water Management, 161(3): 169-182.

Guidolin, M. et al., 2016. A weighted cellular automata 2D inundation model for rapid flood analysis. Environmental Modelling \& Software, 84: 378-394.

Guidolin, M. et al., 2012. CADDIES: a new framework for rapid development of parallel cellular automata algorithms for flood simulation, 10th International Conference on Hydroinformatics (HIC 2012), Hamburg, Germany.

Guillaume, J.H., Jakeman, A., 2012. Providing scientific certainty in predictive decision support: the role of closed questions, Sixth International Congress on Environmental Modelling and Software (iEMSs), Leipzig, Germany.

Haasnoot, M. et al., 2014. Fit for purpose? Building and evaluating a fast, integrated model for exploring water policy pathways. Environmental Modelling \& Software, 60(Supplement C): 99-120.

Hammond, M.J., Chen, A.S., Djordjević, S., Butler, D., Mark, O., 2015. Urban flood impact assessment: A state-of-the-art review. Urban Water Journal, 12(1): 14-29.

IPCC, 2014. Summary for Policymakers, Cambridge University Press, Cambridge, United Kingdom and New York, NY, USA.

Kalyanapu, A.J., Shankar, S., Pardyjak, E.R., Judi, D.R., Burian, S.J., 2011. Assessment of GPU computational enhancement to a 2D flood model. Environmental Modelling \& Software, 26(8): 1009-1016.

Krupka, M., 2009. A rapid inundation flood cell model for flood risk analysis, Heriot-Watt University.

Krupka, M., Pender, G., Wallis, S., Sayers, P., Mulet-Marti, J., 2007. A rapid flood inundation model, Proceedings of the congress-international association for hydraulic research. Citeseer, pp. 28.

Kuczera, G. et al., 2006. Joint probability and design storms at the crossroads. Australasian Journal of Water Resources, 10(1): 63-79.

Leandro, J., Chen, A.S., Schumann, A., 2014. A 2D parallel diffusive wave model for floodplain inundation with variable time step (P-DWave). Journal of Hydrology, 517: 250-259.

Leandro, J., Martins, R., 2016. A methodology for linking 2D overland flow models with the sewer network model SWMM 5.1 based on dynamic link libraries. Water Science and Technology, 73(12): 3017-3026.

Leitão, J.P., Boonya-aroonnet, S., Prodanović, D., Maksimović, Č., 2009. The influence of digital elevation model resolution on overland flow networks for modelling urban pluvial flooding. Water Science and Technology, 60(12): 3137-3149.

Lhomme, J., Bouvier, C., Mignot, E., Paquier, A., 2006. One-dimensional GIS-based model compared with a two-dimensional model in urban floods simulation. Water Science and Technology, 54(6-7): 83-91.

Lhomme, J. et al., 2008. Recent development and application of a rapid flood spreading method. 
Löwe, R. et al., 2017. Assessment of urban pluvial flood risk and efficiency of adaptation options through simulations - A new generation of urban planning tools. Journal of Hydrology, 550: 355-367.

M.H., M.F., 2010. Flood damage estimation beyond stage-damage functions: an Australian example. Journal of Flood Risk Management, 3(1): 88-96.

Maksimović, Č. et al., 2009. Overland flow and pathway analysis for modelling of urban pluvial flooding. Journal of Hydraulic Research, 47(4): 512-523.

Mark, O., Weesakul, S., Apirumanekul, C., Aroonnet, S.B., Djordjević, S., 2004. Potential and limitations of 1D modelling of urban flooding. J. Hydrol., 299: 284.

Melbourne Water, 2007. Port Phillip and Westernport Region Flood Management and Drainage Strategy.

Merz, B., Kreibich, H., Schwarze, R., Thieken, A., 2010. Review article "Assessment of economic flood damage". Nat. Hazards Earth Syst. Sci., 10(8): 1697-1724.

Mimura, N. et al., 2014. Adaptation planning and implementation. In: Field, C.B. et al. (Eds.), Climate Change 2014: Impacts, Adaptation, and Vulnerability. Part A: Global and Sectoral Aspects. Contribution of Working Group II to the Fifth Assessment Report of the Intergovernmental Panel of Climate Change. Cambridge University Press, Cambridge, United Kingdom and New York, NY, USA, pp. 869-898.

Moftakhari, H.R., AghaKouchak, A., Sanders, B.F., Matthew, R.A., 2017. Cumulative hazard: The case of nuisance flooding. Earth's Future, 5(2):214-223.

Néelz, S., Pender, G., 2010. Benchmarking of 2D Hydraulic Modelling Packages, Environment Agency.

Néelz, S., Pender, G., 2013. Benchmarking the latest generation of 2D hydraulic modelling packages. SC120002, Environment Agency, Environment Agency.

Olesen, L., Löwe, R., Arnbjerg-Nielsen, K., 2017. Flood Damage Assessment Literature Review and Recommended Procedure, Cooperative Research Centre for Water Sensitive Cities, Melbourne, Australia.

Rahman, A., Hoang, T., Weinmann, E., Laurenson, E., 1998. Joint Probability Approaches to Design Flood Estimation: A Review, CRC for Catchment Hydrology

Rahman, A., Weinmann, P.E., Hoang, T.M.T., Laurenson, E.M., 2002. Monte Carlo simulation of flood frequency curves from rainfall. Journal of Hydrology, 256(3-4): 196-210.

Rossman, L.A., 2015. Storm Water Management Model User's Manual Version 5.1. National Risk Management Research Laboratory, Office of Research and Development, US Environmental Protection Agency Cincinnati, Washington, DC, 353 pp.

Savage, J.T.S., Bates, P., Freer, J., Neal, J., Aronica, G., 2016. When does spatial resolution become spurious in probabilistic flood inundation predictions? Hydrological Processes, 30(13): 2014-2032.

Seyoum Solomon, D., Vojinovic, Z., Price Roland, K., Weesakul, S., 2012. Coupled 1D and Noninertia 2D Flood Inundation Model for Simulation of Urban Flooding. Journal of Hydraulic Engineering, 138(1): 23-34.

Teng, J. et al., 2017. Flood inundation modelling: A review of methods, recent advances and uncertainty analysis. Environmental Modelling \& Software, 90: 201-216. 
Urich, C. et al., 2013. Modelling cities and water infrastructure dynamics. Proceedings of the Institution of Civil Engineers - Engineering Sustainability, 166(5): 301-308.

Vacondio, R., Dal Palù, A., Mignosa, P., 2014. GPU-enhanced Finite Volume Shallow Water solver for fast flood simulations. Environmental Modelling \& Software, 57: 60-75.

van Dijk, E., van der Meulen, J., Kluck, J., Straatman, J.H.M., 2014. Comparing modelling techniques for analysing urban pluvial flooding. Water Science and Technology, 69(2): 305-311.

Velasco, M., Cabello, À., Russo, B., 2016. Flood damage assessment in urban areas. Application to the Raval district of Barcelona using synthetic depth damage curves. Urban Water Journal, 13(4): 426-440.

WBM, B., 2008. TUFLOW User Manual-GIS Based 2D/1D Hydrodynamic Modelling, Report.

Wolfs, V., Willems, P., 2013. A data driven approach using Takagi-Sugeno models for computationally efficient lumped floodplain modelling. Journal of Hydrology, 503(Supplement C): 222-232.

Wright, L., Esward, T., 2013. Fit for purpose models for metrology: a model selection methodology, Journal of Physics: Conference Series. IOP Publishing, pp. 012039.

XPSolutions, 2017. Complete Stormwater, Sewer and Floodplain Model.

Zhang, S., Pan, B., 2014. An urban storm-inundation simulation method based on GIS. Journal of Hydrology, 517: 260-268.

Zhang, S., Wang, T., Zhao, B., 2014a. Calculation and visualization of flood inundation based on a topographic triangle network. Journal of Hydrology, 509: 406-415.

Zhang, S., Xia, Z., Yuan, R., Jiang, X., 2014b. Parallel computation of a dam-break flow model using OpenMP on a multi-core computer. Journal of Hydrology, 512: 126-133.

Zhou, Q., Mikkelsen, P.S., Halsnæs, K., Arnbjerg-Nielsen, K., 2012. Framework for economic pluvial flood risk assessment considering climate change effects and adaptation benefits. Journal of Hydrology, 414-415: 539-549.

Figure 1. Schematic structure of RUFIDAM; thick boxes are modelling modules and dashed-line boxes show flow information and data between modules

Figure 2. Plan and schematic view of the floodplain calculation domain divided into IZs with the associated communication points, accumulation points and underground drainage system (adapted from Bernini and Franchini (2013) and Lhomme et al. (2008))

Figure 3. Example of filling/ spilling routine in the modified rapid flood inundation model

Figure 4. Three catchments studied, located in south eastern Melbourne. Background map (source: Esri, DigitalGlobe, GeoEye, Earthstar Geographics, CNES/Airbus DS, USDA, USGS, AEX, Getmapping, Aerogrid, IGN, IGP, swisstopo, and the GIS User Community)

Figure 5. Comparison of maximum water level at nodes and total link flow in 1D ponding and spilling simulations against dynamic (1D-2D MIKE FLOOD) results for Catchment 3 during the 100-year flood event. 
Figure 6. Differences in the estimated maximum node levels $(\mathrm{m})$ and total flow in links $\left(\mathrm{m}^{3}\right)$ between dynamic 1D-2D MIKE FLOOD and with: spilling configuration (left); and with ponding configuration (right). Maximum water levels and flows obtained from the 1D2D MIKE-FLOOD simulation were subtracted from the results obtained in the 1D simulation. The number labels show surcharge volumes in static 1D simulation (zero surcharges are not labelled). The corresponding maximum flood level simulated by the $1 \mathrm{D}-$ 2D MIKE FLOOD model is presented in the background.

Figure 7. Boxplots of PE, Fit and Bias indexes (see Section 2.2.3) for different 1D model configurations, as well as varying constant head $(\Delta \mathrm{z})$ and minimum IZ area parameters. Black lines indicate the mean value.

Figure 8. Maximum flood extent with depth above $5 \mathrm{~cm}$ in Catchment 1 predicted by the rapid inundation model and 2D MIKE FLOOD, and pixel by pixel comparison of depths.

Figure 9. Fit, Bias, PE (see Section 2.2.3) and flood damage costs calculated by MIKE FLOOD (M) and RUFIDAM (R) for all three catchments and return periods

Figure 10. Maximum flood extent and damage cost predicted by MIKE-FLOOD (a) and (c), and RUFIDAM (b) and (d) in Catchment 3 for 100-year flood (Source: Esri, DigitalGlobe, GeoEye, Earthstar Geographics, CNES/Airbus DS, USDA, USGS, AEX, Getmapping, Aerogrid, IGN, IGP, swisstopo, and the GIS User Community)

Figure 11. Simulation time of RUFIDAM and MIKE FLOOD for all catchments and return periods

- A rapid urban flood inundation and damage assessment model (RUFIDAM) is developed.

- Different model configurations are evaluated through a sensitivity analysis.

- Rapid flood models are suitable for predicting flood extent and depths.

- RUFIDAM is most suitable to compare mitigation solutions for damage reduction. 


\section{RUFIDAM}

(Rapid Urban Flood Inundation and Damage Assessment Model)

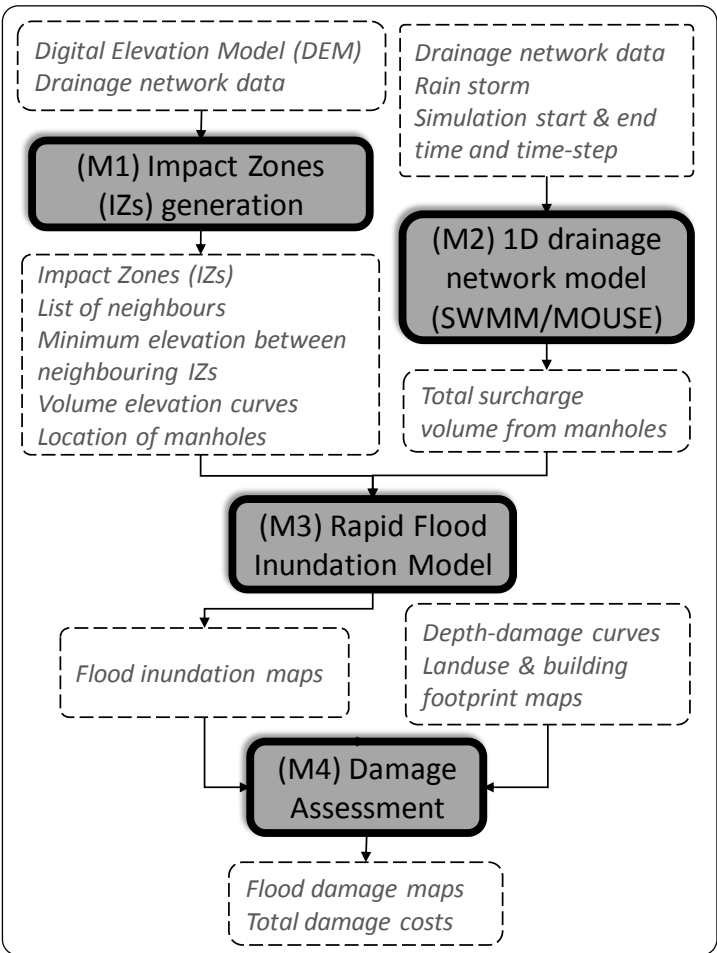




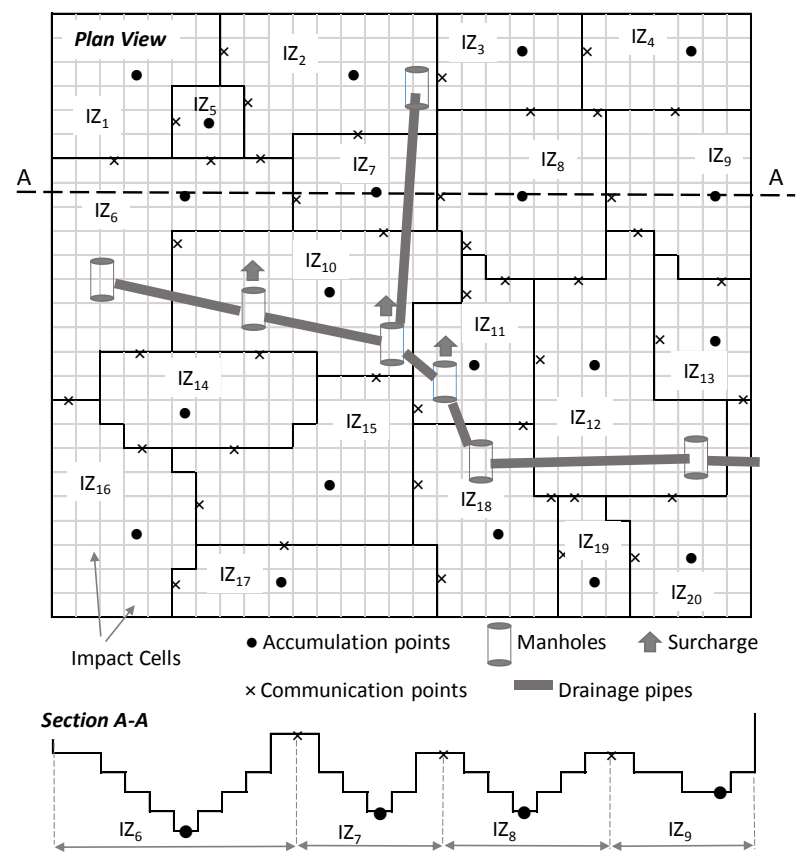


(1) $\begin{array}{llllllllll}I Z_{1} & I Z_{2} & I Z_{3} & I Z_{4} & I Z_{5} & I Z_{6} & I Z_{7} & I Z_{8}\end{array}$

(2) $\begin{array}{rlllllll}I Z_{1} & I Z_{2} & I Z_{3} & I Z_{4} & I Z_{5} & I Z_{6} & I Z_{7} & I Z_{8}\end{array}$ elevation
5.

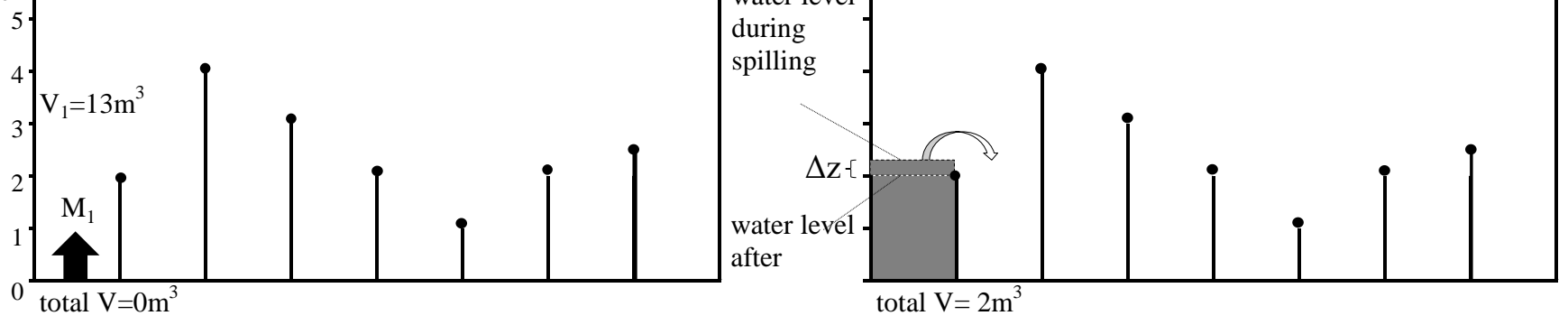

(3) $\begin{array}{lllllll}I Z_{1,2} & I Z_{3} & I Z_{4} & I Z_{5} & I Z_{6} & I Z_{7} & I Z_{8}\end{array}$ elevation
5.

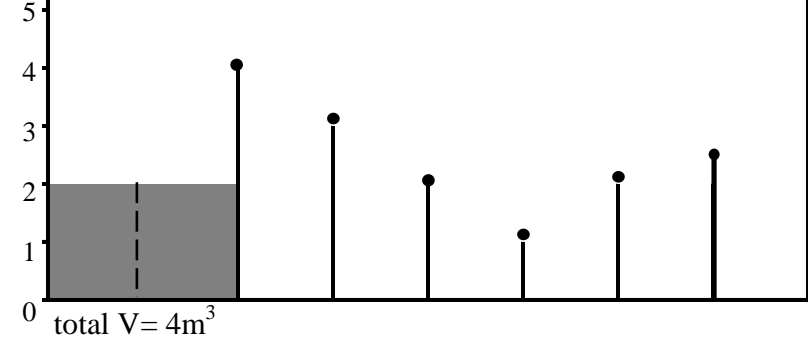

(5) $\begin{array}{lllllllll}I Z_{1,2} & I Z_{3} & I Z_{4} & I Z_{5} & I Z_{6} & I Z_{7} & I Z_{8}\end{array}$ elevation Inac. Inac. $\underline{\text { Act. dry dry dry dry }}$

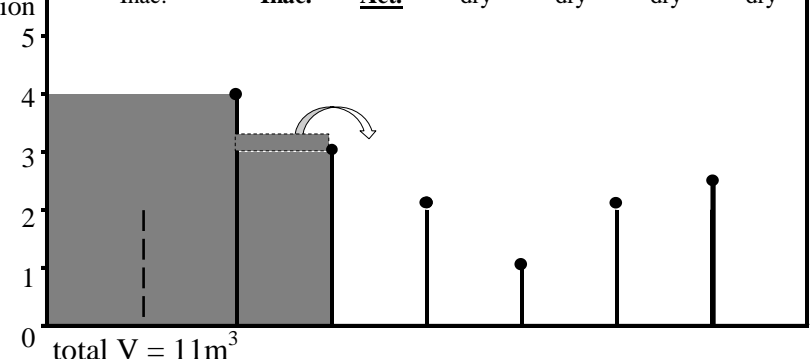

(7) $\begin{array}{llllllll}I Z_{1,2} & I Z_{3} & I Z_{4} & I Z_{5} & I Z_{6} & I Z_{7} & I Z_{8}\end{array}$ elevation
5. Inac. Act. Inac. dry dry dry dry

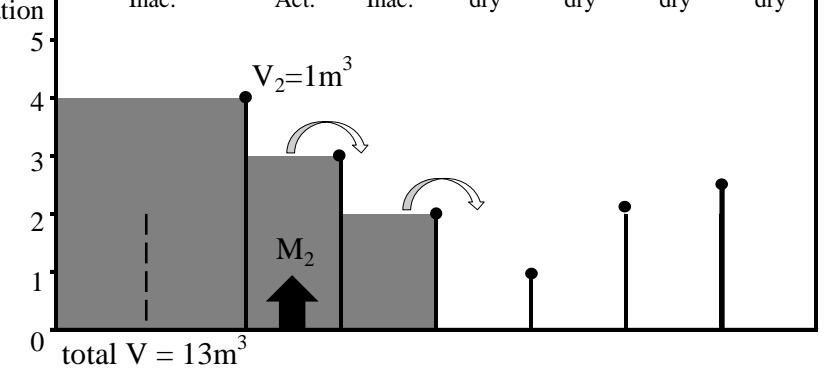

(9) $\begin{array}{lllllllll}I Z_{1,2} & I Z_{3} & I Z_{4} & I Z_{5} & I Z_{6} & I Z_{7} & I Z_{8}\end{array}$ elevation Inac. Inac. Inac. dry dry

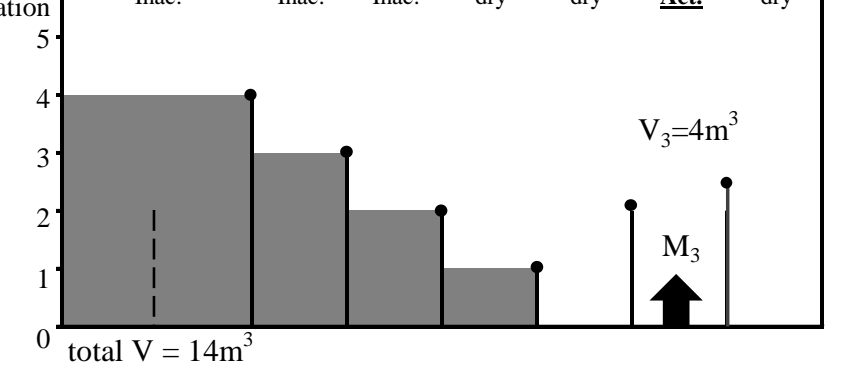

Legend

(1) iteration number
(4). $\begin{array}{llllllll}I Z_{1,2} & I Z_{3} & I Z_{4} & I Z_{5} & I Z_{6} & I Z_{7} & I Z_{8}\end{array}$

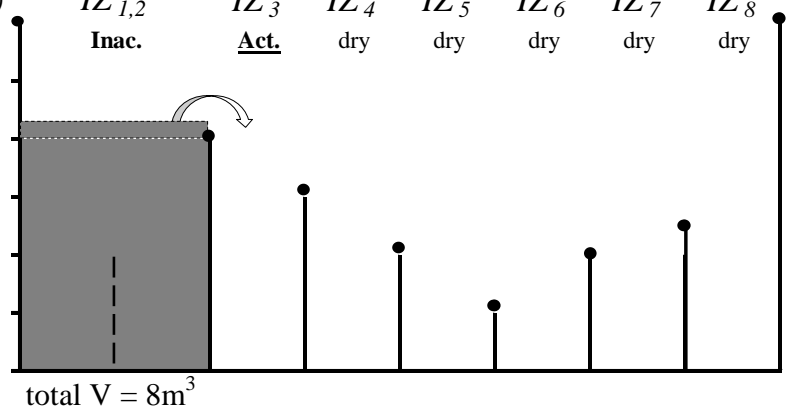

(6) $\begin{array}{llllllll}I Z_{1,2} & I Z_{3} & I Z_{4} & I Z_{5} & I Z_{6} & I Z_{7} & I Z_{8}\end{array}$

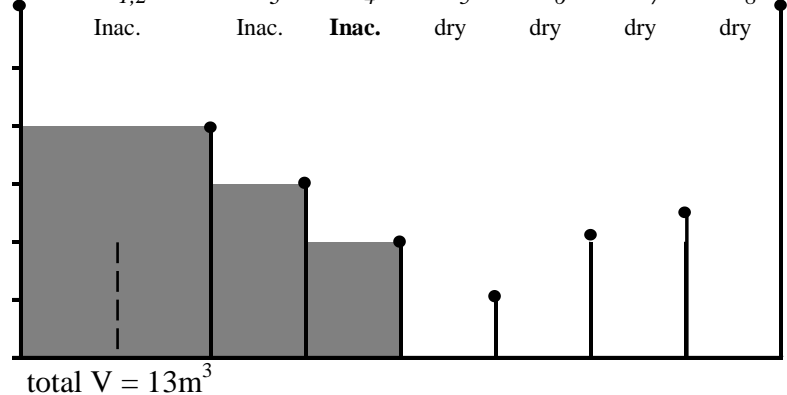

(8). $\begin{array}{llllllll}I Z_{1,2} & I Z_{3} & I Z_{4} & I Z_{5} & I Z_{6} & I Z_{7} & I Z_{8}\end{array}$

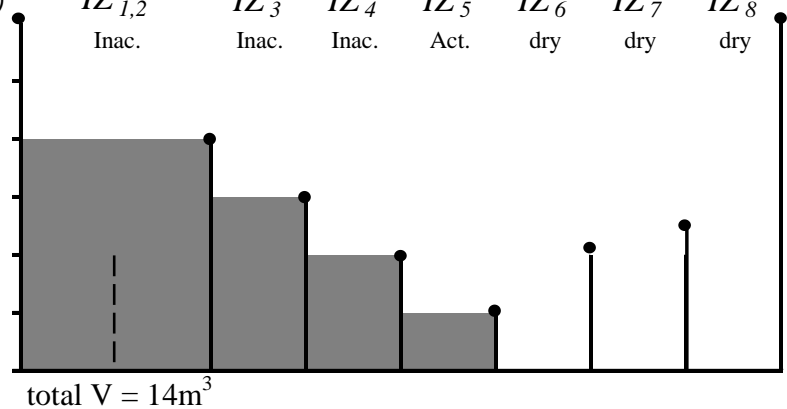

(10) $\begin{array}{llllllll}I Z_{1,2} & I Z_{3} & I Z_{4} & I Z_{5} & I Z_{6} & I Z_{7} & I Z_{8}\end{array}$

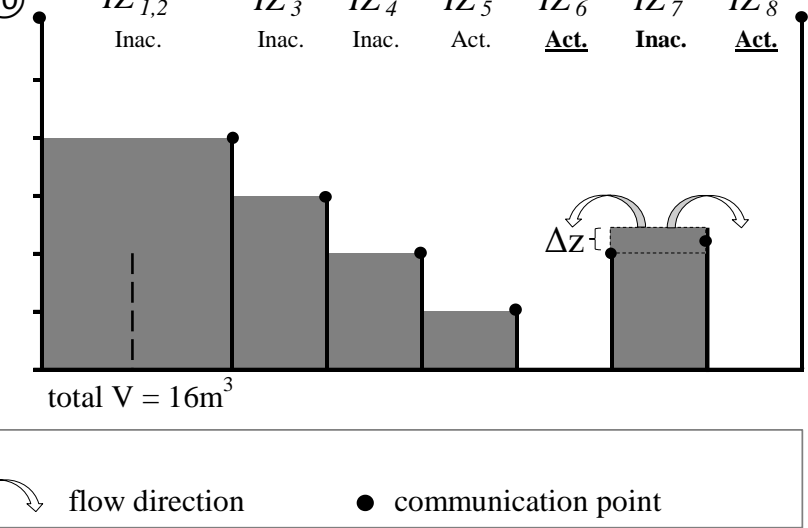




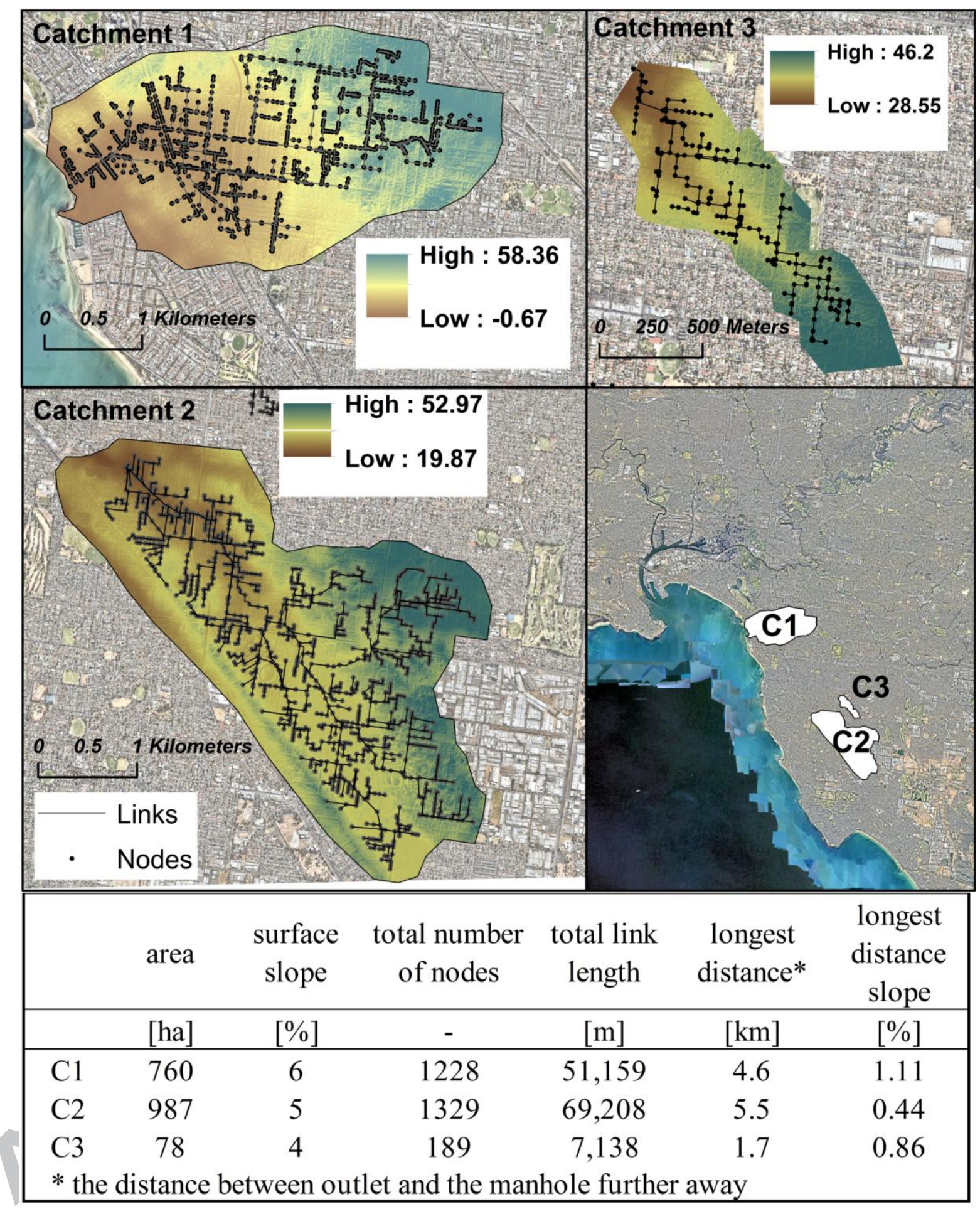



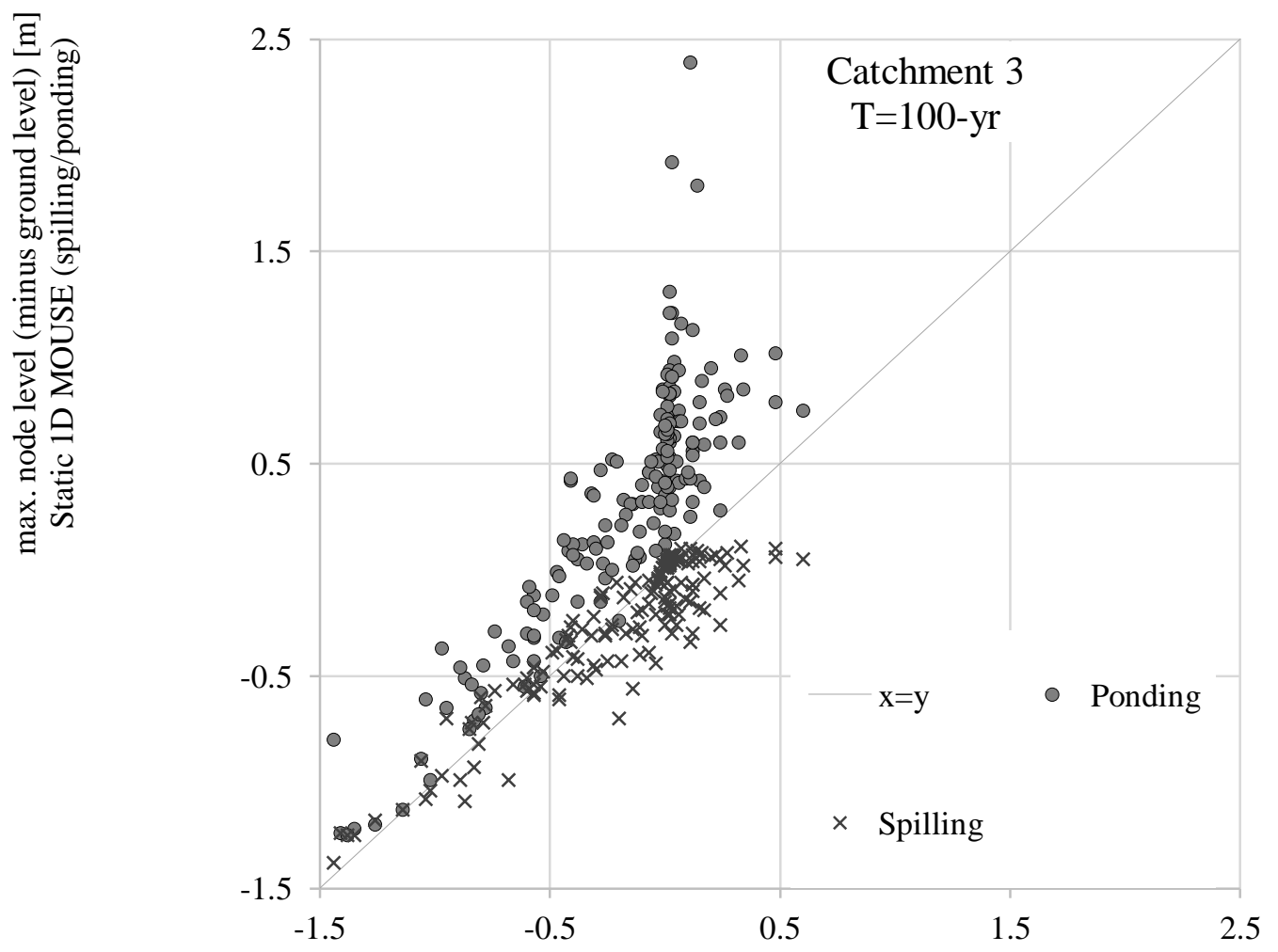

max. node level (minus ground level) [m] dynamic 1D-2D MIKE FLOOD 

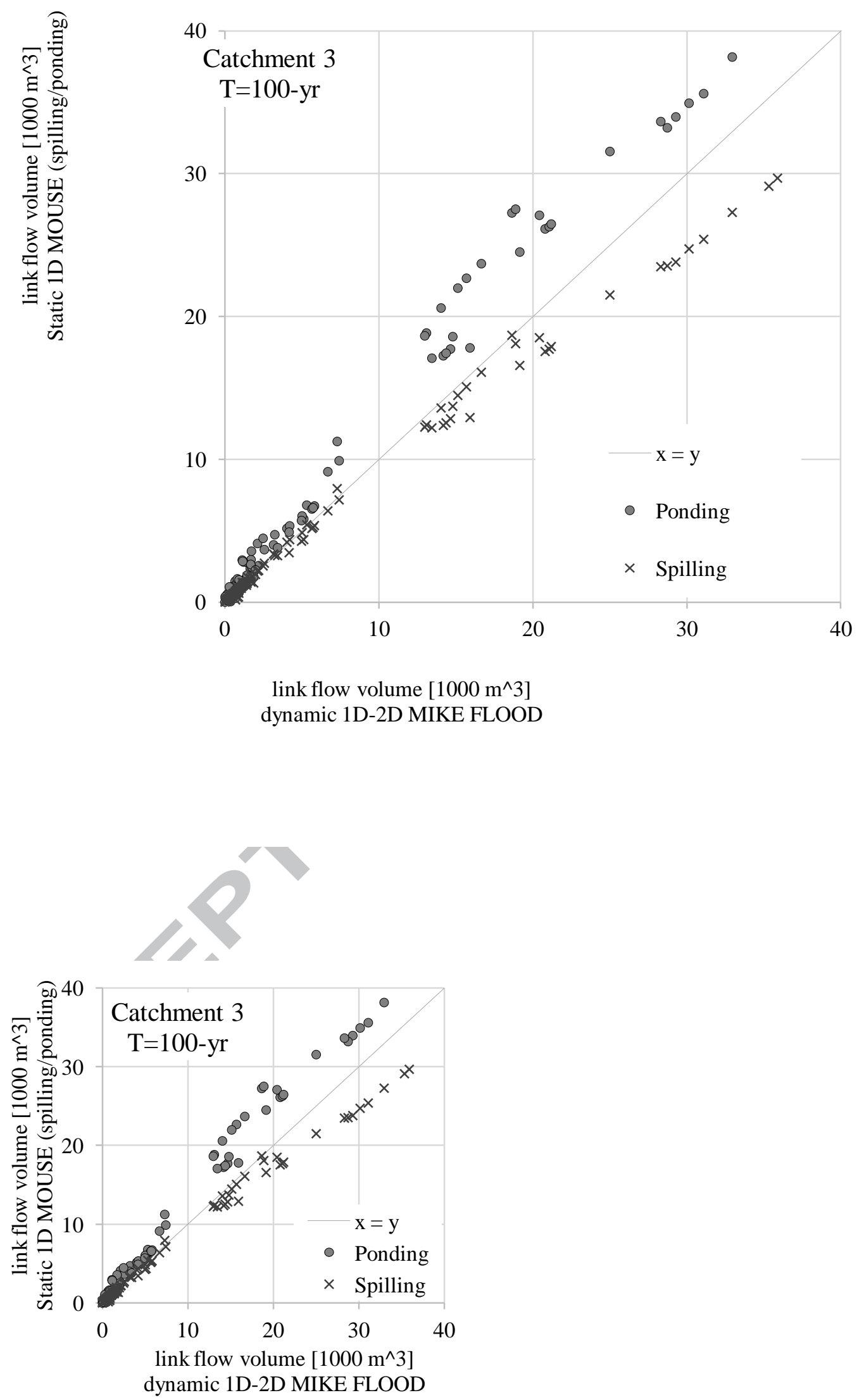

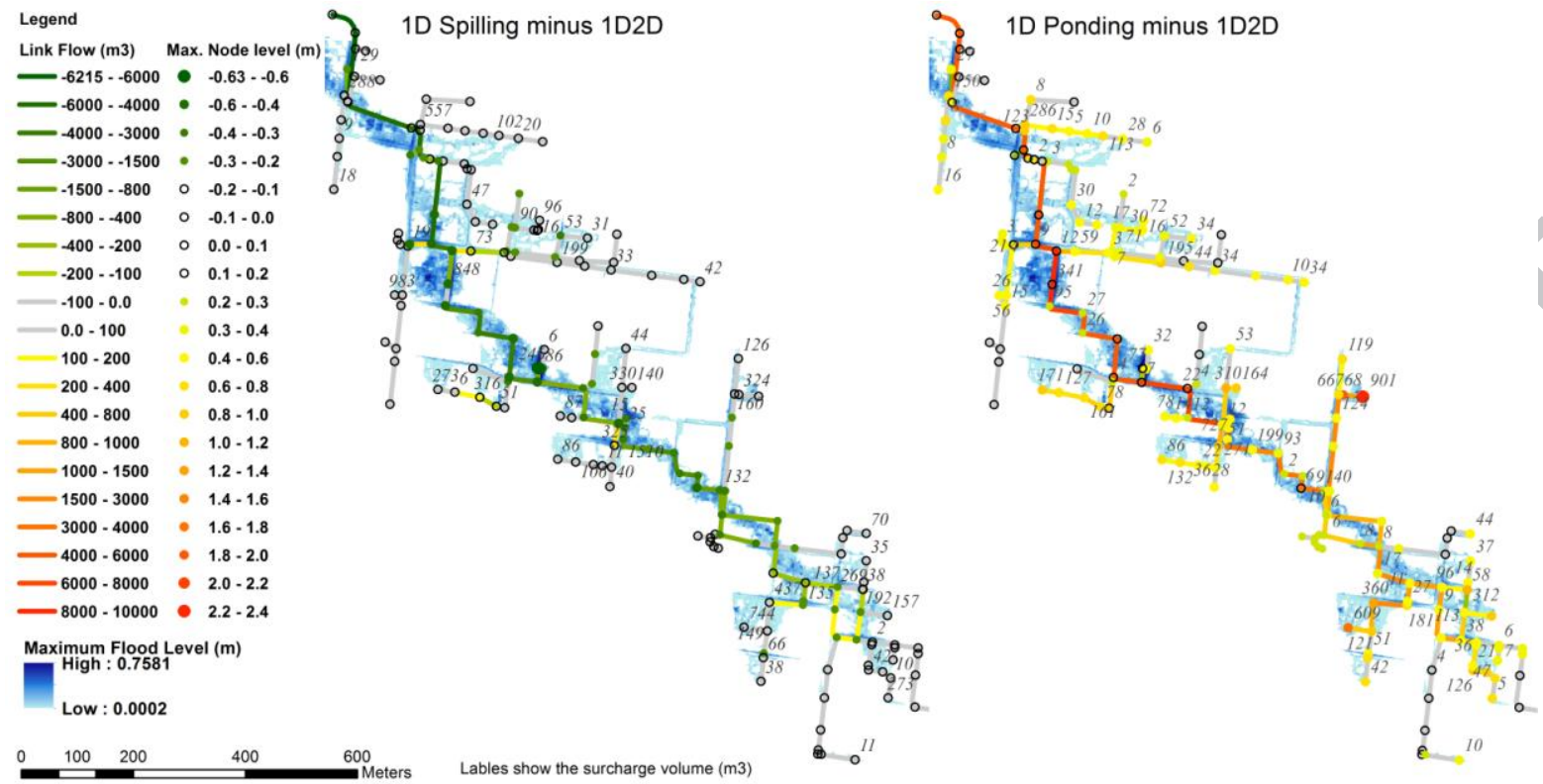

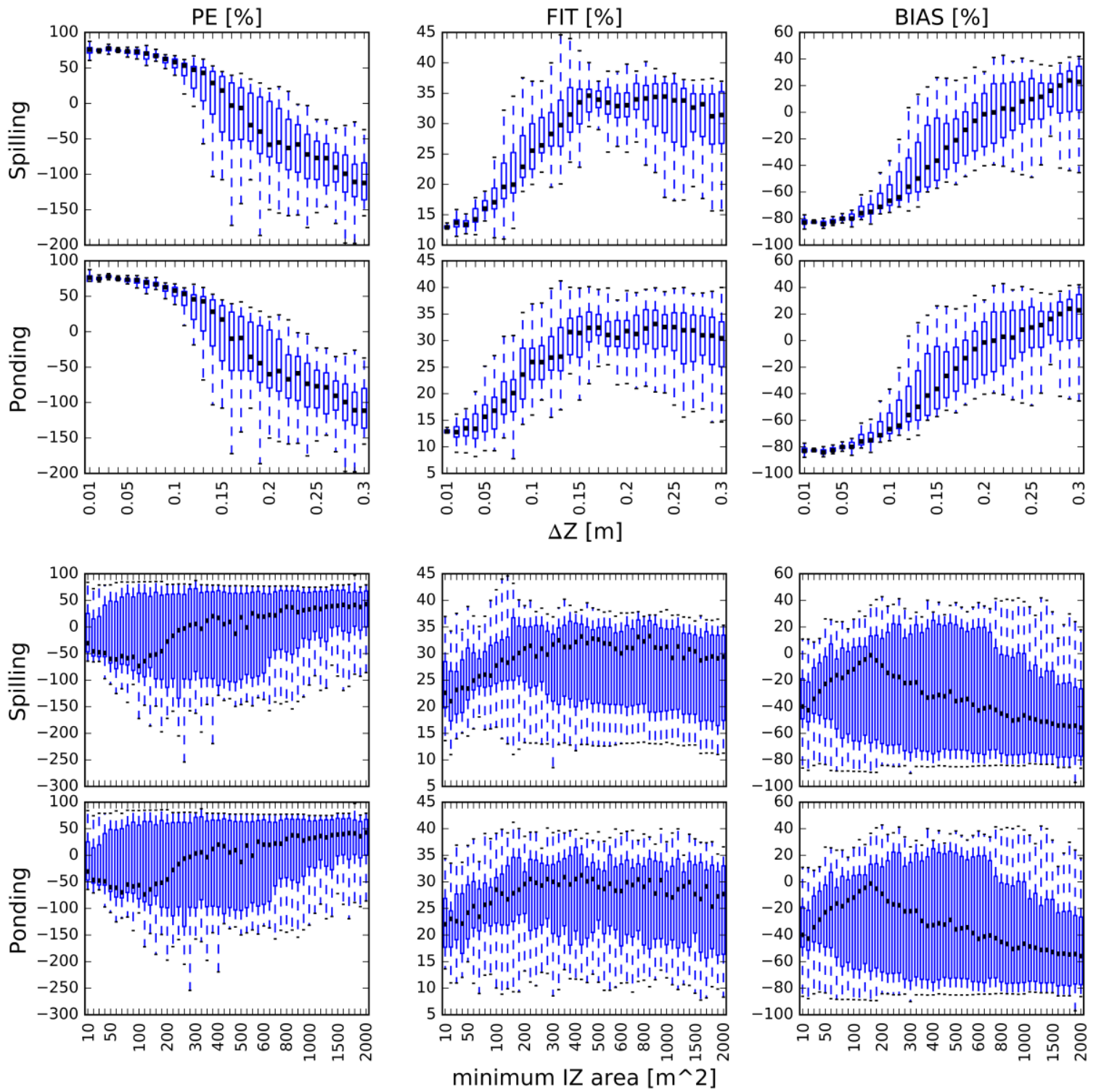

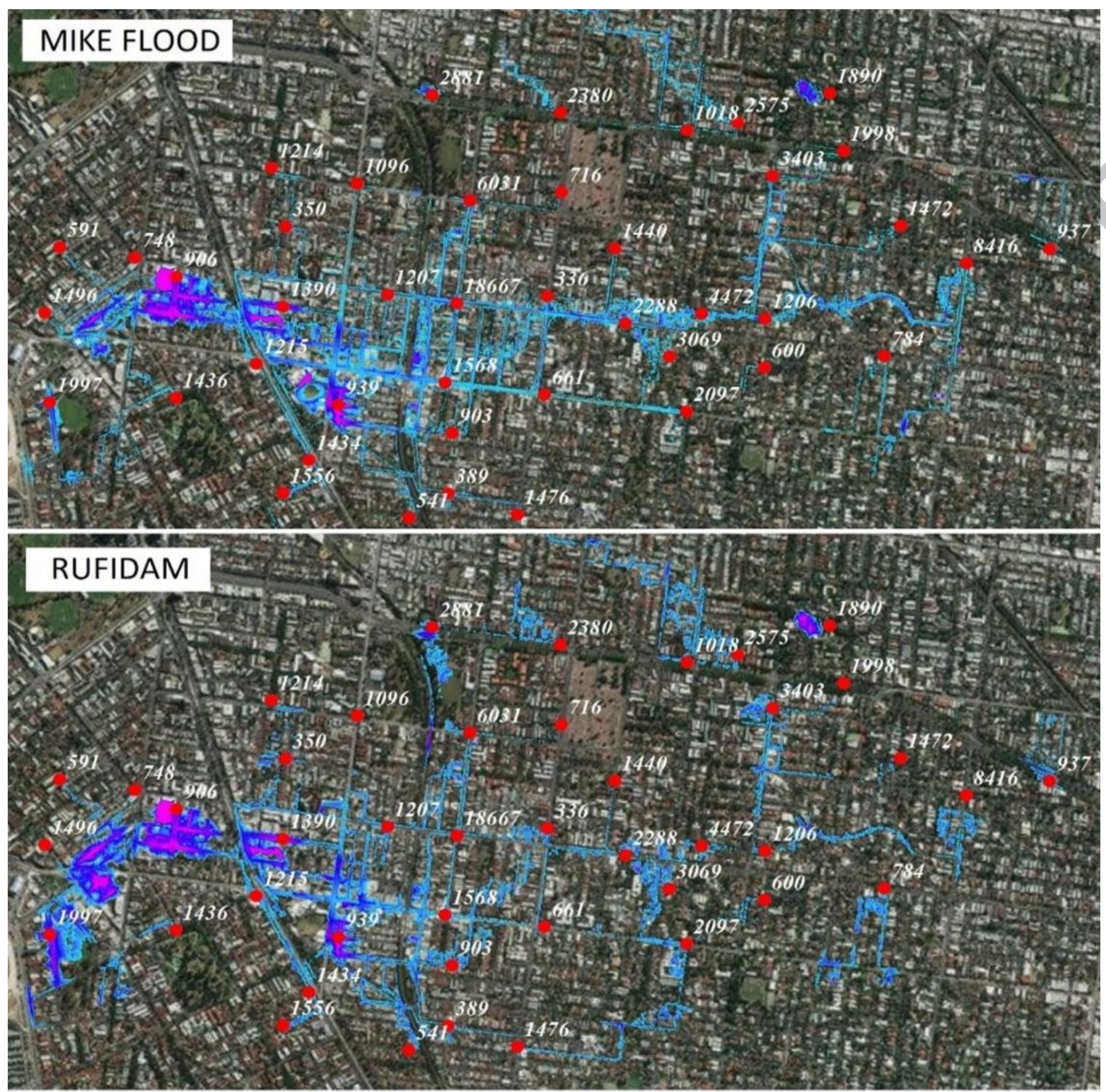

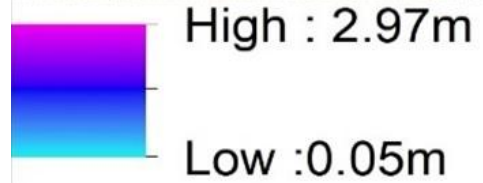

Surcharge location and volumes (m3)

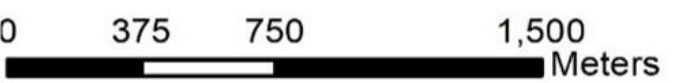

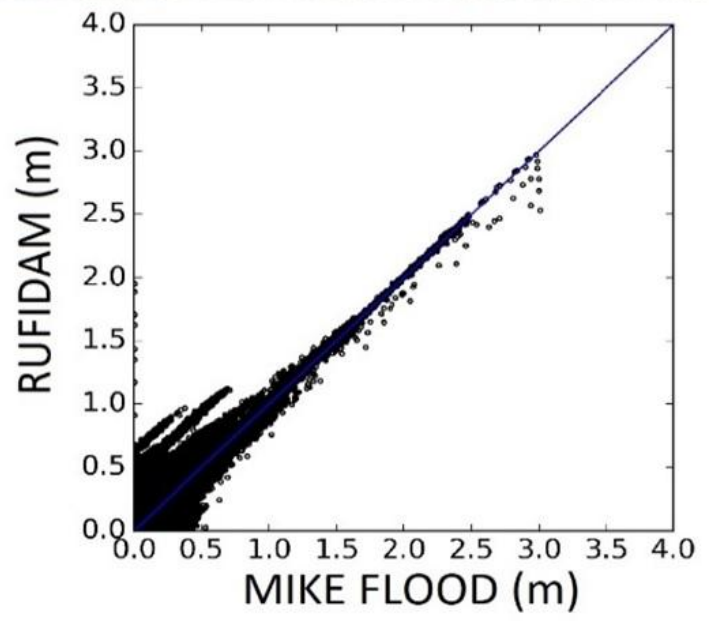




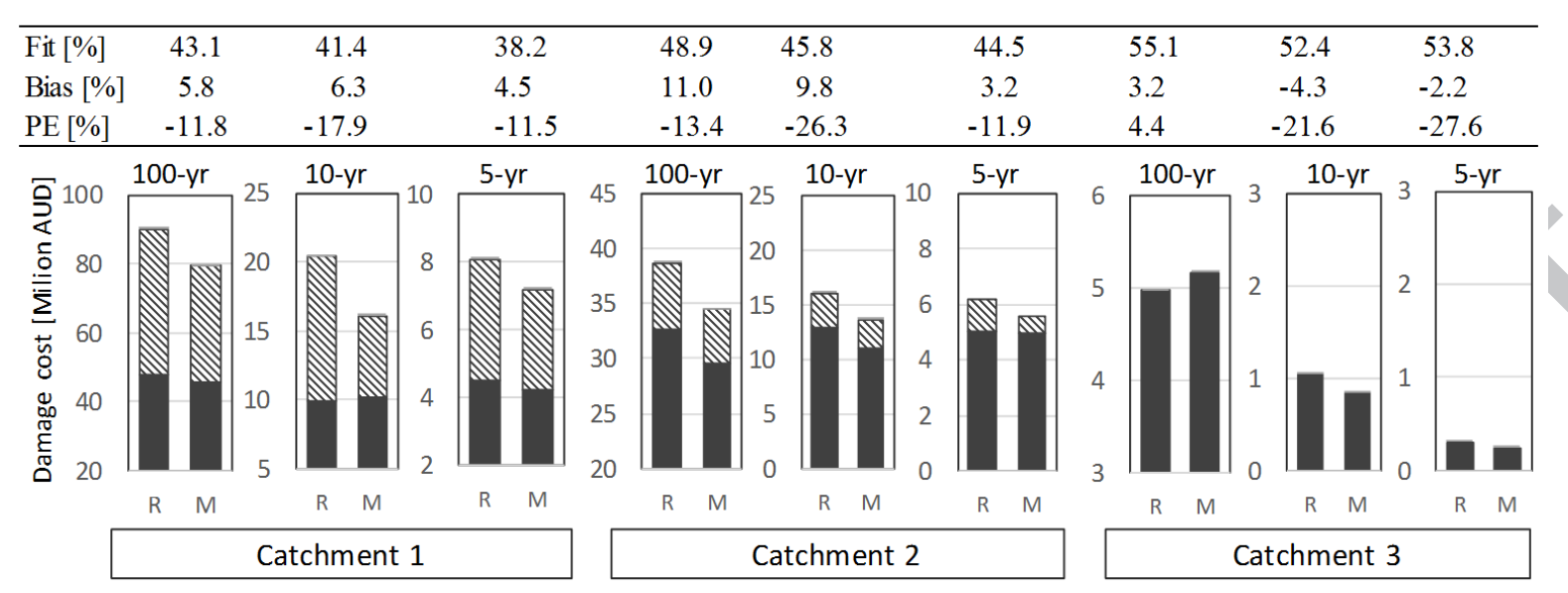

- Res damage $\mathbb{Q}$ Com/Ind damage $\mathbf{n}$ Road damage 

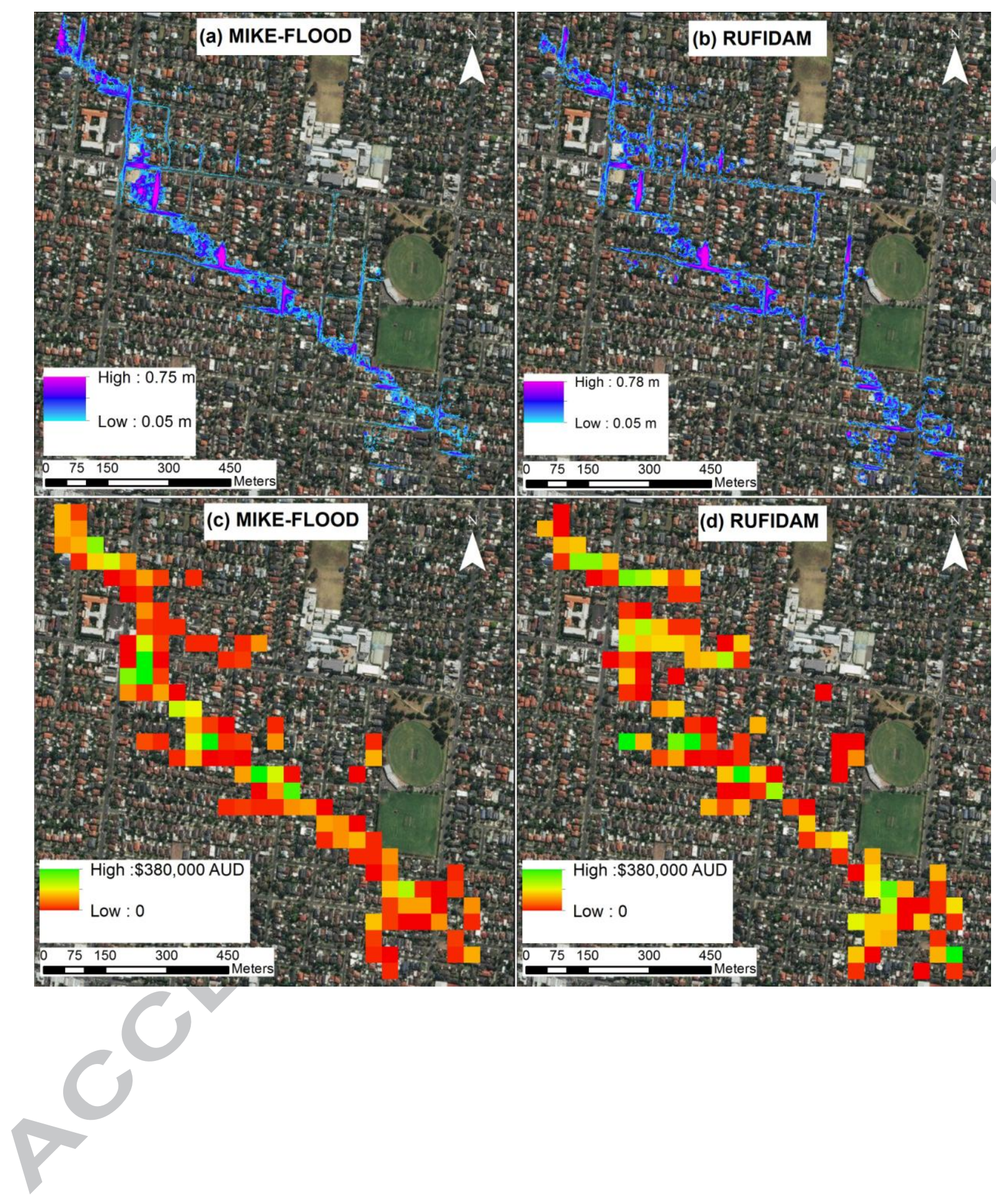


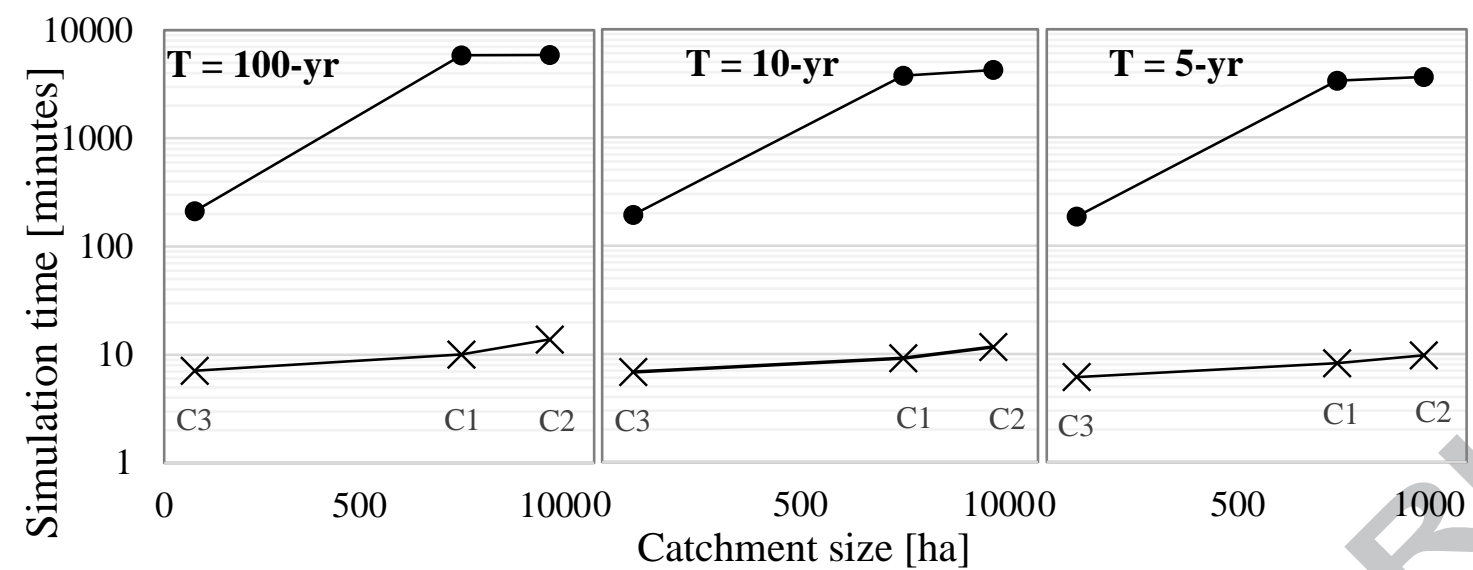

$\leftarrow$ RUFIDAM - MIKE FLOOD Area: C3 $=78$ ha $\mid \mathrm{C} 1=760$ ha $\mid \mathrm{C} 2=987$ ha 


\section{Supporting Material for "RUFIDAM: A Rapid Urban Flood Inundation and Damage Assessment Model"}

\section{S1 Impact Zones (IZs) generation}

The main input data for the pre-processing step is the digital elevation model (DEM) of the floodplain domain. Each cell in the DEM raster file is considered as an impact cell. The ArcPy module (ESRI, 2012) of ArcGIS ${ }^{\mathrm{TM}}$ software was used within the Python programming language to automate this pre-processing step. The hydrology toolbox is used to delineate IZs by first calculating the flow direction and then delineating a raster of basins and converting them to a polygon shapefile of IZs. At this stage, those IZs that are smaller than the minimum IZ area (specified as model parameter), are selected and merged with their neighbours that have the largest areas in the neighbourhood using the Eliminate tool in ArcGIS (Figure S1). By converting the polygons of IZs into polylines, a shapefile can be extracted that includes the neighbouring information of IZ polygons. Each line in the extracted polyline feature represents the boundary of two neighbouring IZs. Using the Stack Profile tool, the elevation data along each line (one point per grid cell) is extracted from the DEM. The minimum elevation of each profile is the communication level of two neighbouring IZs. The Zonal Statistics as Table tool is used to extract impact cell elevation values within each IZ. Given the water elevation, the stored volume in each IZ can be calculated as the difference between water level and impact cell elevation and their area. The location of the nodes in 1D models are linked to the IZs using the Spatial Join tool. All the extracted data is then stored in a database on disk to be used by the rapid flood inundation model.
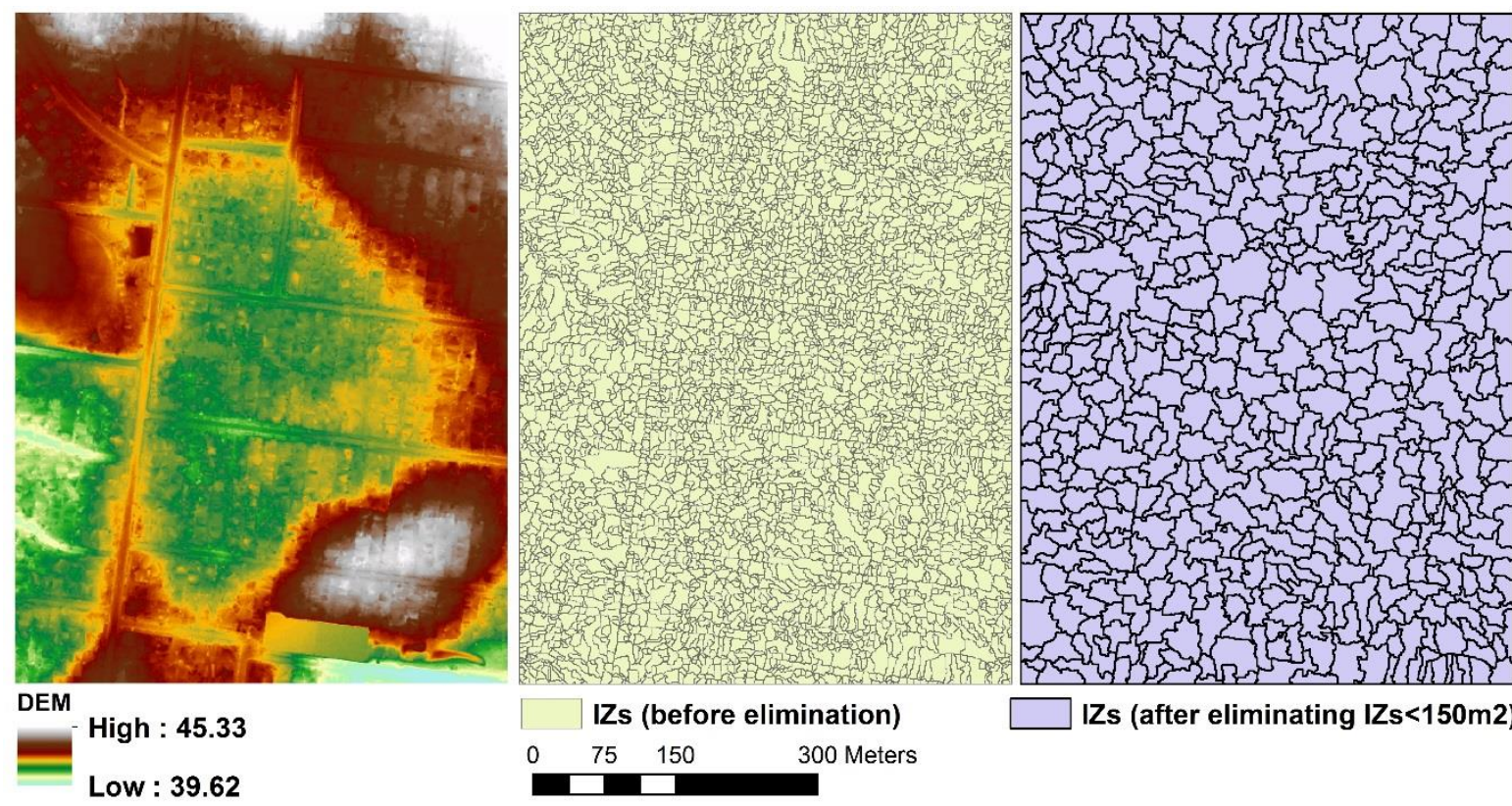

IZs (after eliminating IZs $<150 \mathrm{~m} 2$ )

Figure S1. Example of the generated Impact Zones (IZs) from a 1m resolution DEM (left) and after eliminating IZs that are smaller than $150 \mathrm{~m}^{2}$ 


\section{S2 Rapid flood inundation model routine}

A flow diagram of the adapted RFSM in this study is given in Figure S2. At the start of the simulation, all IZs are dry. The routine starts with spreading the surcharge volume of the first manhole. Due to the nature of the routine, the order of selecting manholes has no impact on the final calculated flood extent. Initially the IZ that locates the first surcharging manhole becomes active. Water level is then raised to the lowest communication point(s) greater than the current water level (which is initially zero). If the located neighbour has the same water level as the active IZ, they merge together and stay active for the next iteration. Otherwise, the active IZ will flow to the found IZ(s). The total flood volume spread over IZs is calculated and if it is equal or greater than the surcharge volume of manhole one, the spreading process starts for manhole 2 after changing the status of active IZ(s) to inactive. Otherwise, all active IZ(s) become inactive and selected IZs become active (except the merged IZs that should remain active). If the condition of the located IZ is dry, it becomes active for the next iteration. Otherwise, it means that the selected IZ(s) is already flowing to another IZ. The algorithm then searches for all inactive IZs that are receiving flow from the selected IZ but not flowing to any neighbouring IZs and change their condition to active. The next iteration starts with filling water in active IZs and spilling to the selected neighbouring IZs. Finally, the total flood volume is equal or greater than the total flood volume from the surcharging manholes, the algorithm stops and creates flood extent and depth maps.

The filling/spilling routine described here only accounts for volume transfers, but, in reality, the movement of water from one IZ to another requires an extra driving head, $\Delta \mathrm{z}$, to overcome friction and other head loss (Krupka, 2009). Therefore, when estimating the maximum water level in each IZ, an additional head should be added above the level of the lowest link. The value of $\Delta z$ can either be set constant for all links in the domain or it can be calculated for each link individually to account for the local flow conditions (Krupka, 2009). In this study we used the constant extra head approach. 


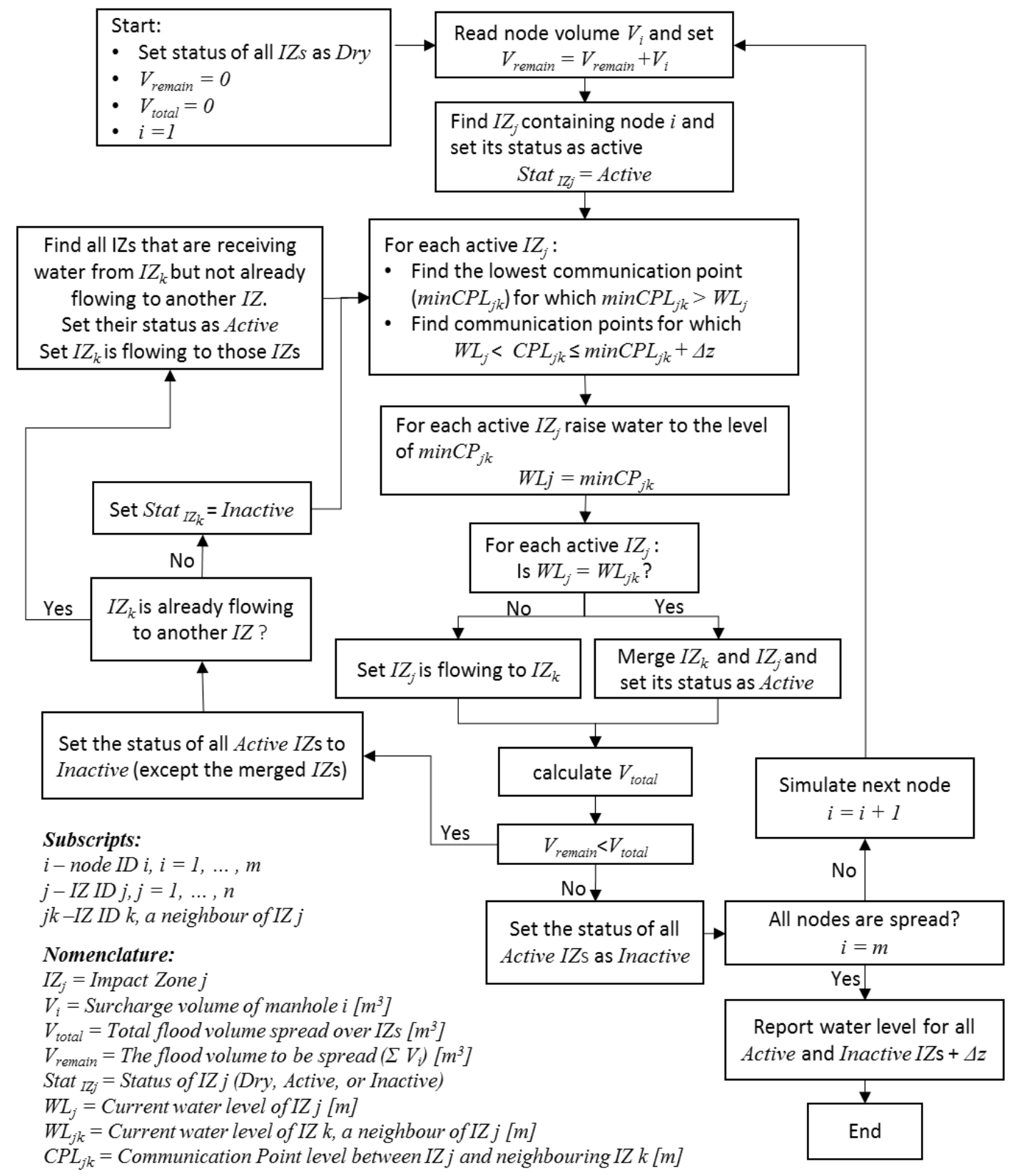

Figure S2. Flowchart for the adapted rapid flood spreading algorithm

Figure S3 shows an example of the filling and merging process for a case where flooding originates from an IZ that is located within a large natural depression. As shown in this Figure, the impact zones are merging together as the flood extent grows and at step 7, we can see that the local depression becomes one single IZ formed by merging the 6 initial IZs. 

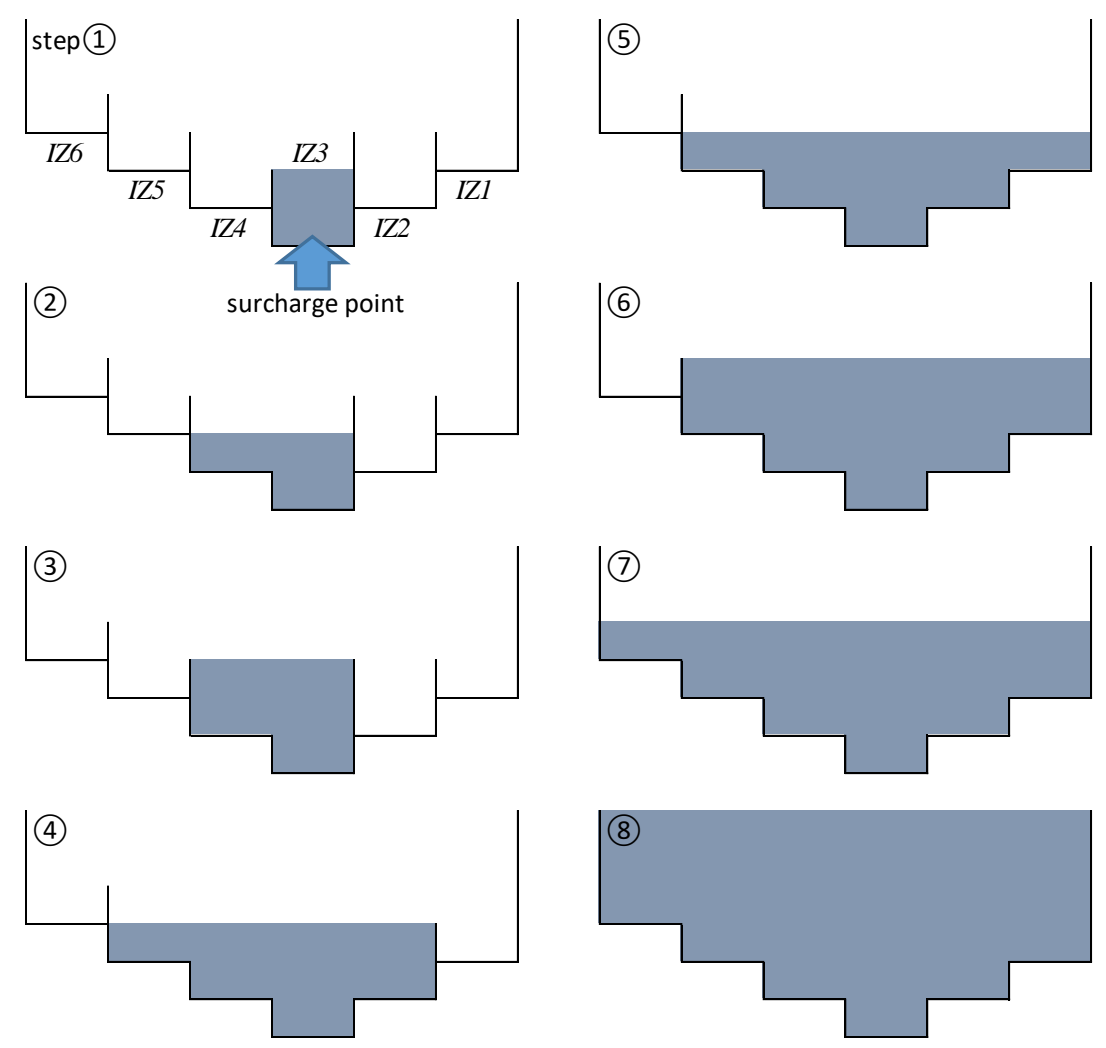

Figure S3. Process of filling and merging of impact zones located within a larger depression

\section{S3. Impact Zones (IZs) specifications}

Table S1 shows the number of initially identified IZs and final IZs after elimination for each catchment. The number of IZs were reduced by merging IZs that have areas smaller than $150 \mathrm{~m}^{2}$. The minimum IZ area parameter was selected based on the Sensitivity Analysis results.

Table S1. Number of initially created and final IZs (after merging IZs that have area smaller than $\left.150 \mathrm{~m}^{2}\right)$

\begin{tabular}{lcccccc}
\hline & area & $\begin{array}{c}\text { number of } \\
\text { initially } \\
\text { generated IZs } \\
\text { [thousands }]\end{array}$ & $\begin{array}{c}\text { number of IZs after } \\
\text { elimination }(\text { minim } \\
\left.\text { IZ are }=150 \mathrm{~m}^{2}\right) \\
\text { [thousands }]\end{array}$ & $\begin{array}{c}\text { minimum } \\
\mathrm{IZ} \text { area } \\
{[\mathrm{ma}]}\end{array}$ & $\begin{array}{c}\text { average IZ } \\
\text { area }\end{array}$ & $\begin{array}{c}\text { maximum } \\
\mathrm{IZ} \text { area }\end{array}$ \\
\hline Catchment 1 & 760 & 950.8 & 112.0 & 150 & 220 & 1589 \\
Catchment 2 & 987 & $1,047.5$ & 136.0 & 150 & 249 & 1835 \\
Catchment 3 & 78 & 118.4 & 14.2 & 150 & 206 & 1125 \\
\hline
\end{tabular}




\section{S4 Typical time series pattern for SIP1 experiment}

Figure S4 shows the typical surcharge time series considered for all source points as input to MIKE FLOOD. In order to generate the inflow time series, we multiplied the total surcharge volume of each node by the time series pattern.

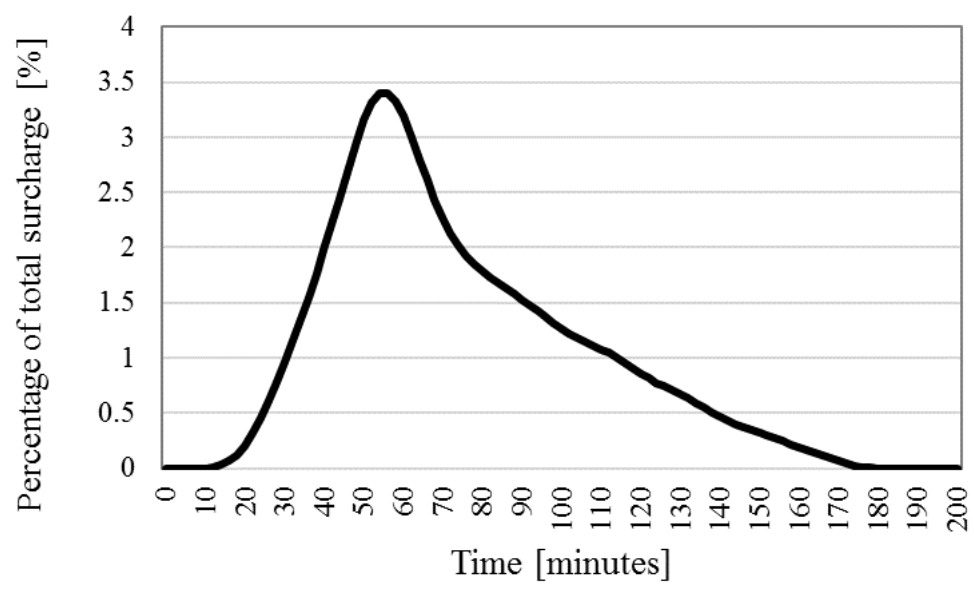

Figure S4. Typical surcharge time series pattern

${ }^{1}$ Surface Inundation Prediction 


\section{S5 Static vs. dynamic 1D drainage network simulation (SVD experiment)}

Figures S5 compares maximum water levels obtained in the static 1D drainage network simulations with ponding and spilling configurations, against those obtained from a dynamic (1D-2D MIKE FLOOD) simulation for all catchments and return periods. Figure S6 does this same comparison for link flow volumes.

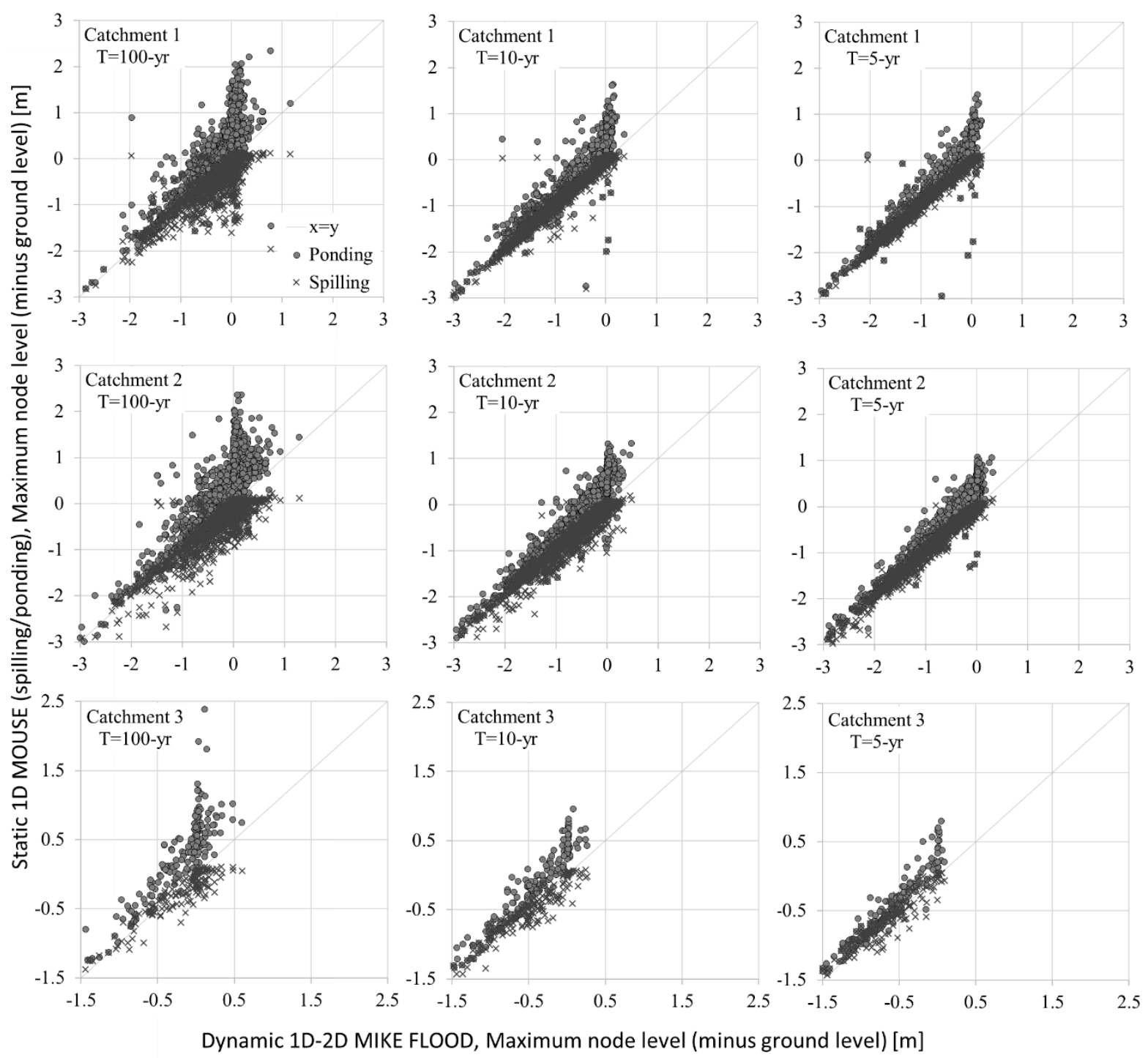

Figure S5. Comparison of maximum water level at nodes in 1D ponding and spilling simulations against dynamic (1D-2D MIKE FLOOD) results for all catchments and return periods. 

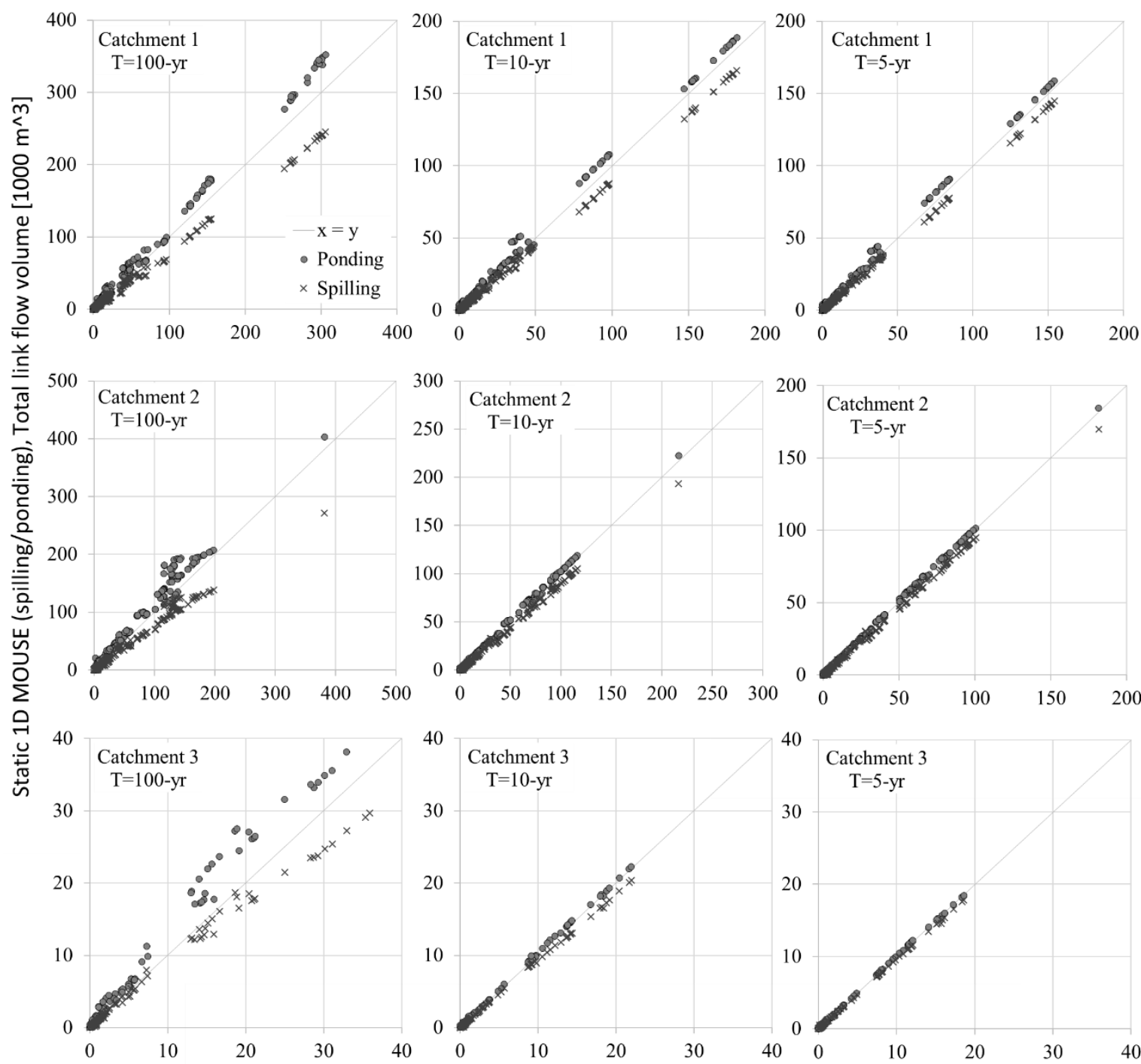

Dynamic 1D-2D MIKE FLOOD, Total link flow volume [1000 $\mathrm{m}^{\wedge} 3$ ]

Figure S6. Comparison of total link flows in 1D ponding and spilling simulations against dynamic (1D-2D MIKE FLOOD) results for all catchments and return periods. 


\section{S6. Model parameter sensitivity analysis using the hydraulic performance indicators}
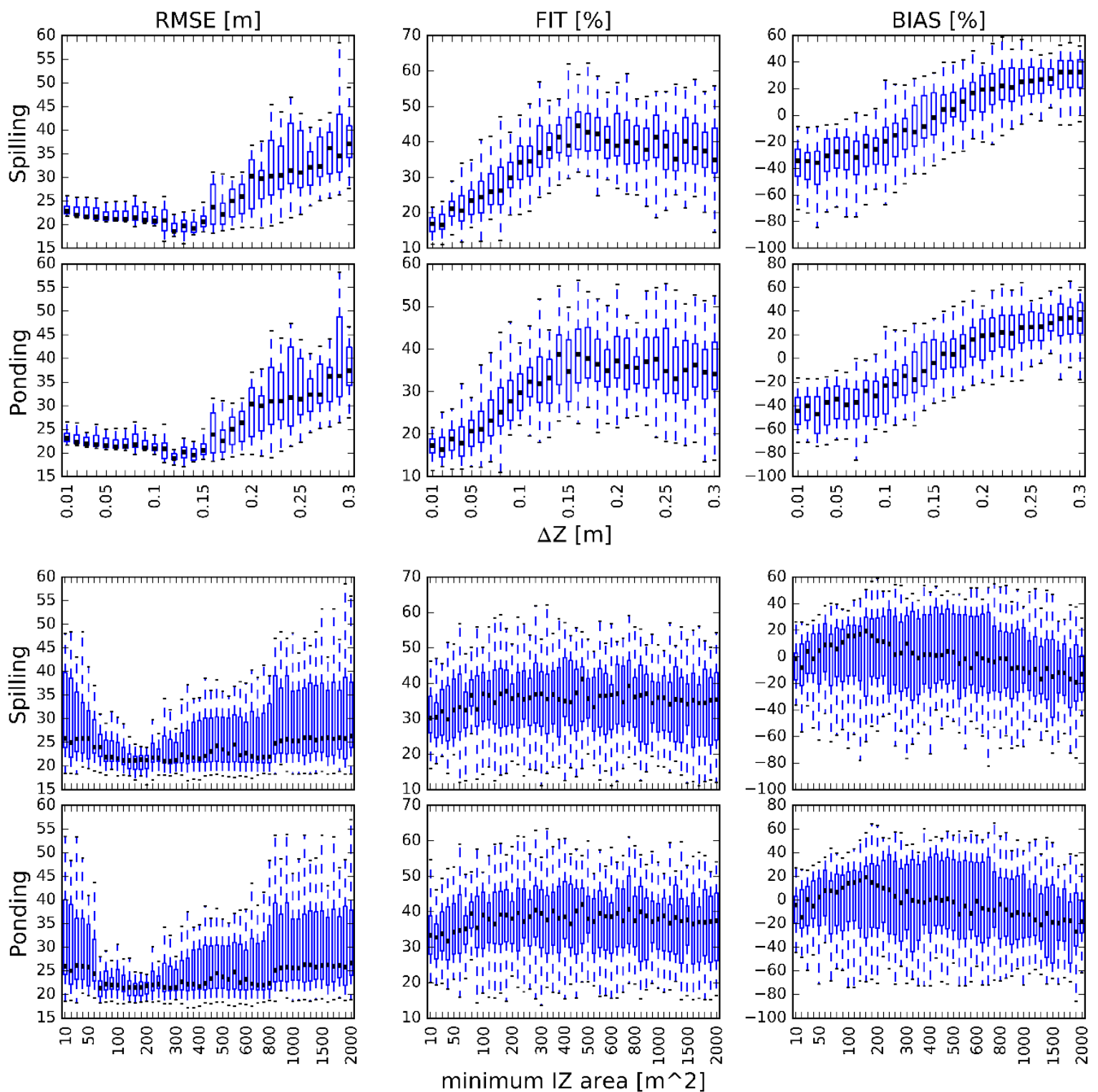

Figure S7. Boxplots of RMSE, Fit and Bias indexes for different 1D model configurations, as well as varying constant head $(\Delta z)$ and minimum IZ area parameters. Black lines indicate the mean value. 